\title{
Effect of the Current Density in the Electrical Resistance Sintering Technique to Fabricate a $\beta$-Ti-Nb- Sn Ternary Alloy for the Biomedical Sector
}

\section{Mariana Rossi ( $\square$ mrncorrea90@gmail.com )}

Sao Paulo State University Julio de Mesquita Filho: Universidade Estadual Paulista Julio de Mesquita Filho https://orcid.org/0000-0002-1476-5990

\section{Montserrat Vicenta Haro Rodríguez}

Universitat Politècnica de València: Universitat Politecnica de Valencia

\section{Angel Vicente Escuder}

Universitat Politècnica de València: Universitat Politecnica de Valencia

\section{Eber de Santi Gouvêa}

Universitat Politècnica de València: Universitat Politecnica de Valencia

Margarida Juri Saeki

Sao Paulo State University Julio de Mesquita Filho: Universidade Estadual Paulista Julio de Mesquita Filho

Vicente Amigó Borrás

Universitat Politècnica de València: Universitat Politecnica de Valencia

\section{Research Article}

Keywords: Powder Metallurgy, Microstructure, $\beta$-Ti, Corrosion resistance, Biomaterial

Posted Date: August 26th, 2021

DOl: https://doi.org/10.21203/rs.3.rs-614356/v1

License: () (i) This work is licensed under a Creative Commons Attribution 4.0 International License. Read Full License 


\section{Abstract}

The electrical resistance sintering is a fast method to fabricate metallic samples in the field of metallurgy and it was used to obtain the Ti-Nb-Sn alloy to be applied as biomaterial, variyng different electrical current densities $(11,12$ and $13 \mathrm{kA})$. The powders were obtained by mechanical alloying, then they were compacted at pressure of $193 \mathrm{MPa}$ during $700 \mathrm{~ms}$. The structure and microstructure of the powders and the samples was evaluated by x-ray diffraction, by Field Emission Scanning Electron Microscopy and electron backscattered diffraction. The mechanical properties were evaluated by microhardness assay and corrosion resistance was made in Ringer Hartmann's solution at $37^{\circ} \mathrm{C}$. The samples are formed by $a, a^{\prime \prime}$ and phase $\beta$. The $\%$ of phase $\beta$ in the samples obtained at 11,12 and $13 \mathrm{kA}$ was $96.56,98.12$ and 98.02 respectively. The peripheral zone present more presence of microporosity than the central zone. The microstructure is also formed by bcc- $\beta$ grains equiaxial, and the samples obtained at $12 \mathrm{kA}$ present better homogeneity of the microstructure. The grain size increased with the increase of the electrical current density. The microhardness are in the range of $389-418 \mathrm{HV}$ and decreased with the increase of electrical current density. Corrosion tests proved excellent corrosion resistance of the alloys $\left(0.24-0.45 \mu \mathrm{A} / \mathrm{cm}^{2}\right)$. The standard deviation of kinetic parameters of the samples at 11 and $13 \mathrm{kA}$ were very higher, related to the lack of homogeneity of the microstructure.

\section{Introduction}

The studies about metallic alloys based on titanium for application in orthopedics is a field in a constantly development, due to the inconveniences of commercial metallic prostheses that lead to long-term failure and to rejection by the body. The main characteristics required to the success of these biomaterials are nontoxicity, good resistance to corrosion and elastic modulus close to bone tissue [1-3]. It is known that metallic materials based on cobalt, chromium, aluminum, vanadium and nickel promote allergenic and carcinogenic effects, in addition to proven respiratory and neurological disorders [4,5]. Corrosion resistance is closely linked to the chemical composition of these materials, such as the content of elements stabilizing hcp (a phase) and bcc ( $\beta$ phase) crystalline structures and the type of processing that was employed, which will interfere with their microstructure and morphology. Regarding the elastic modulus, most of the employed materials have higher values than that of the bone tissue, such as $\mathrm{Co}-\mathrm{Cr}$, Ti-6Al-4V or Ti-CP alloys [6,7]. This difference leads to the adaptive bone resorption, which lasts for 10 to 15 years, when the patient needs surgery for repairing and replacement of the prosthesis [8]. This phenomenon arises due to the cushioning effect whereby the bone absorbs all the charge loaded on the prosthesis as its elastic modulus is larger. The bone is daily discouraged and its fragility intensifies around the device causing the prosthesis to lose stability. In the short term, these effects are not observed. However, a prosthesis that requires bone healing, which will be inserted to remain in the pacient for life, tends to fail in the face of this problem. In order to repair such inconveniences, $\mathrm{Ti}$ alloys based on $\mathrm{Nb}$ and $\mathrm{Sn}$ have been studied as it is known $\mathrm{Nb}$ (beta isomorphic type stabilizer) and Sn (neutral element) are elements that do not present toxicity and are good candidates for making $\mathrm{Ti}$ alloys with lower elastic modulus [9] and increased mechanical strength [10]. Based on phase diagram of the $\mathrm{Ti}-\mathrm{Nb}$ binary system [11], $\mathrm{Nb}$ exhibits complete solubility in $\mathrm{Ti}$ above $882^{\circ} \mathrm{C}$, which allows to study its influence over the entire range of $\mathrm{Nb}$ content in a system and to observe the modification of its properties by diffusion process $[11,12]$. At lower temperature, it is possible to notice two stable phases $(\alpha+\beta)$, 
but rapid cooling of the $\beta$ phase results in a structure composed by metastable phases. In the case of Ti-Nb system, this sudden cooling results in the martensitic transformation of the $\beta$ phase, which can result in the $a^{\prime}$ or a" phases depending on $\mathrm{Nb}$ content [13]. The effects of $\mathrm{Nb}$ content on the mechanical properties of $\mathrm{Ti}-\mathrm{Nb}$ alloy and its relationship to the $\beta$ phase content were evaluated by Yahaya et al. preparing these alloys by powder metallurgy (PM) [14]. It was found that up to $35 \%$ (wt\%) of $\mathrm{Nb}$, the alloy do not cryistallize as a phase. However, under higher contents of $\mathrm{Nb}$, such as $45 \%$ (wt\%), resulted in less resistent alloy to the compression, despite of lower elastic modulus (13.46GPa). In general, the the alloy with 35 (wt\%) of $\mathrm{Nb}$ presented the most adequate characteristics regarding the microstructure and mechanical properties. In most works on Ti-Nb-Sn alloys, they used spark plasma sintering (SPS) and conventional powder metallurgy (PM) for their preparation. There is a lack in the study on the preparation of these materials by electrical resistance based sintering technique (ERS). It is known that the first patent for electric current sintering was registered in 1906 by Lux [15]. Few years later came Taylor's [16] (in 1933) and Lenel's studies [17] (in the 1950s), who called this technique electrical pressure resistance sintering (ERS). Later, during the 70 and 80 decades, the ERS technique received a new boost mainly by Sovietic and Japanese researchers $[18,19]$. Nowadays, the ERS technique is studied as a modality of the electrical field assisted sintering technique (FAST), which is the common name for the technique based on electrical consolidation of powder metallurgy (PM). During this long period, many FAST variants were developed for use on an industrial scale, as overall ultimate goal [2022]. Most popular FAST is the so-called SPS, in which low-wear (electrically conductive) graphite dies and punches are used, to combine the application of alternating current and vacuum or argon for atmosphere controll.

The ERS technique allows the use of durable electrical insulation matrices, and the process can take place in the air, as a typical cycle being completed in seconds. In addition, the required equipment can be easily adapted from the well-known resistance welding technology, a well-tested technology.

Among the advantages of ERS, compared to PM, there are the use of relatively low pressures (about 100 $\mathrm{MPa}$ ) to reach the final material with very high density, extraordinarily short processing times (about $1 \mathrm{~s}$ or less), and the possibility to operate in the air without the need for a controlled atmosphere [23,24]. The main disadvantages of the ERS technique arise from operational difficulties (incomplete knowledge of parameters and how certain parameters influence the process) and non homogeneous temperature distribution in the powder mass [25]. In order to increase knowledge about the ERS process, especially in the applicability for the consolidation of alloy with a high content of $\beta$ phase stabilizing element, the influence of the electric current on the physical, mechanical and electrochemical characteristics was evaluated in the promising Ti-34Nb-6Sn alloy for its use as medical implant.

\section{Materials And Methods}

\subsection{Powders preparation}

Elemental powders of $\mathrm{Ti}(99.9 \%), \mathrm{Nb}(99.8 \%)$ and $\mathrm{Sn}$ (99.8\%) were purchased from Atlantic Equipment Engineers, which presented particle sizes around $30 \mu \mathrm{m}, 16 \mu \mathrm{m}$ and $17 \mu \mathrm{m}$, respectively. They were weighed in order to obtain alloys with $34(\mathrm{wt} \%) \mathrm{Nb}$ and $6(\mathrm{wt} \%) \mathrm{Sn}$ in a glove box to minimize the contamination of oxygen and nitrogen. 
Then, they were mixed with a process control agent (PCA), $\mathrm{NaCl}$ (in powder) was used, in the amount of 1.5 (wt\%) in relation to the total mass of the powders. The mixture was made for 30 min in a tumbler mixer (Inversina 2L-Bioengineering AG) at $90 \mathrm{rpm}$, followed by $72 \mathrm{~h}$ milling process to promote mechanical alloying. The milling process was carried out at room temperature in a high energy mill (Retsch- PM 400/2), for $72 \mathrm{~h}$ at $240 \mathrm{rpm}$, interspersed with 10 seconds of rest every $8 \mathrm{~min}$ of grinding interval. Before starting the process, the steel vessel was purged by argon for 4 times. The proportion of steel balls ( $5 \mathrm{~mm}$ of radius) used was 10:1 in relation to the powder mass.

\subsection{Synthesis via ERS}

The consolidation of specimen was carried out using the ERS technique in an equipment developed within the EU funded EFFIPRO project, used in collaboration with the AMES Company (Barcelona-ES). The materials were produced in a cylindrical matrix with a diameter of $2.2 \mathrm{~cm}$ and a thickness of $0.55 \mathrm{~cm}$. In order to obtain samples with these dimensions, the density of the alloy of $d_{\text {Ti34Nb6Sn }}=5.52 \mathrm{~g} / \mathrm{cm}^{3}$ was taken into account for the calculation of powder mass. The mixture powder was placed in a silicon nitride die between two tungstencopper electrodes [26] and compacted at pressure of $193 \mathrm{MPa}$. The current intensities tested for consolidation were 11, 12 and $13 \mathrm{kA}$ during 700 ms of sintering time.

\subsection{Phase/chemical and microstructural characterization}

For the characterization and evolution of the current phases as well as the lattice parameters of the powders, was used X-ray diffraction (Bruker/D2Phaser). A Cu Ka radiation ( $=1.541 \AA$ ) was use that works at $30 \mathrm{kV}$ and $10 \mathrm{~mA}$. The measurement was made in the range of angles between 30 and 90 degrees, with a step of $0.02^{\circ}$ every $10 \mathrm{~s}$. The refinement of the structure and the quantitative phase analysis were carried out using the free MAUD software (version 2.94). The phases and diffraction planes were analyzed by comparing the $d$ value of each peak of the diffraction pattern from those of the Inorganic Crystal Structure Database (ICSD). In addition, the crystallites size and induced micro strain in the titanium lattice were calculated from the peak broadening and peak positioning of the X-ray diffraction pattern of the powder milled and the sintered parts according to Williamson-Hall equation [27].

$$
\beta \cos \theta=\frac{k \lambda}{D}+4 \varepsilon \sin \theta(1)
$$

Where $\beta=$ Full width at half maxima, $k=$ shape factor generally taken as 0.9 [28], $\lambda=$ wave length of used radiation in $\mathrm{XRD}, \Theta=$ peak diffraction angle, $D=$ crystalline size and $\varepsilon=$ induced strain in the lattice. $A$ graph was plotted between $4 \sin \theta$ and $\beta^{\star} \cos \theta$ for selected peaks of powder sample, along the $x$ and $y$ axis respectively and a best fitted linear curve is drawn for different Ti peaks.

The particle size distribution was measured using particle size analyzer by laser scattering (Mastersizer 2000Malvern Instruments). Distilled water was used to disperse the powders. To evaluate the contamination by 0 and $\mathrm{N}$, it was used the LECO TCH600 series equipment with an inert gas fusion analyzers.

The microstructure of the powders and the sintered was characterized by Field Emission Scanning Electron Microscopy (FE-SEM) (ZEISS-ULTRA 55) with backscattered electrons (BSE), secondary electrons (SE) and X- 
ray energy dispersive detectors (EDS) (Oxford Instruments Ltda). To characterize more precisely the microstructure, like the grains and the phase quantifications was used electron back-scattered diffraction (EBSD) with a scanning electron microscope (Zeiss-ULTRA 55 operating at $20 \mathrm{kV}$ ) equipped with an Aztec HKL Max System (Oxford Instruments Ltda) under an acceleration voltage of $20 \mathrm{kV}$ with a step size of 0.1 $\mu \mathrm{m}$, selecting the three possible phases to be analyzed, $\beta-\mathrm{Ti}, \mathrm{a}-\mathrm{Ti}$ and $\mathrm{a}^{\prime \prime}-$ martensite. For the powders, they were embedded in resin and prepared metallographically from cross-sections in order to analyze particle size, homogeneity of the $\mathrm{Ti}, \mathrm{Nb}$ and $\mathrm{Sn}$ elements and the evolution of the alloyed process.

\subsection{Microhardness test}

Vickers microhardness tester (HMV-SHIMADZU) was used to evaluate the samples consolidated by ERS. To measure the microhardness was made 12 indents on the surface of each sample applying $490.3 \mathrm{mN}$ (HV $0.05)$ during $12 \mathrm{~s}$. For each indent a distance of $50 \mu \mathrm{m}$ was obeyed.

\subsection{Corrosion resistance in Ringer Hartmann's solution}

The corrosion behavior was studied by measuring the open circuit potential (OCP) for 35 min and potentiodynamic polarization assay after that time in a potentiostat/galvanostat 144 (Metrohm potentiostatPGSTAT204) on a surface of $0.785 \mathrm{~cm}^{2}$, using a conventional three-electrode cell in a Ringer-Hartmann's solution (6<pH $<7),\left(\mathrm{NaCl} 5.7 \mathrm{~g} / \mathrm{L}, \mathrm{KCl} 0.358 \mathrm{~g} / \mathrm{L}, \mathrm{CaCl}_{2} 0.221 \mathrm{~g} / \mathrm{L}\right.$, Lactate $\left.4.956 \mathrm{~g} / \mathrm{L}\right)$ at $37^{\circ} \mathrm{C}$. The $\mathrm{Ag} / \mathrm{AgCl}$ electrode was used as a reference electrode and $\mathrm{Pt}$ thread as auxiliary one. All potential values were expressed in relation to this reference electrode hereinafter as well as the current density was normalized by geometric area. The electrochemical tests consisted of OCP measurement (for $35 \mathrm{~min}$ ) and polarization from OCP to $2 \mathrm{mV} / \mathrm{s}$ scan rate. The corrosion parameters as the Tafel slopes $\left(b_{a}\right.$ and $\left.b_{c}\right)$ in the region of cathodic and anodic process domains, corrosion potential $\left(\mathrm{E}_{\text {corr }}\right)$ and corrosion current $\left(\mathrm{I}_{\text {corr }}\right)$ were determined using Wolfram Mathematica 12.1 software. The Electrochemical Impedance Spectroscopy (EIS) technique was followed within the $100 \mathrm{kHz}-5 \mathrm{mHz}$ frequency range with a sinu-soidal amplitude wave of $0.01 \mathrm{~V}$ on Eocp. Potentiodynamic polarization curves were carried out by swiping the potential from $1 \mathrm{~V}$ to $3 \mathrm{~V}$ at the $2 \mathrm{mV} / \mathrm{s}$ scan rate. The parameters were acquired by the Zview 3.5 software by fitting equivalent circuits. Chronoamperometric tests were carried out at $1 \mathrm{~V}$ (passivation potential) for 5 min with a $0.01 \mathrm{~s} \mathrm{time} \mathrm{interval}$ for data acquisition in the previously prepared sample.

\section{Results And Discussion}

For the analysis of particle size (seen in table 1), it is noted that after the milling process by mechanical alloying (MA), the mixture showed a reasonable decrease in particle size, with the average obtained being similar than the initial size of the $\mathrm{Nb}$ and $\mathrm{Sn}$, but smaller than the initial titanium particles. The maximum particle size found was higher than the initial size of the 3 elements $\mathrm{Ti}, \mathrm{Nb}$ and $\mathrm{Sn}$, approximately $171 \mu \mathrm{m}$. It is certain that the MA process promotes a significant reduction in the size of the particles over time, and also promotes their agglomeration due to the more interaction of the surface promoted by to the reduction of sizes. Another factor that contributes to the agglomeration process is the cold welding effect and the increase in temperature during the constant impacts of the balls and the friction caused between the balls and the 
powders. The use of PCA tends to diminish these effects. However, even with the use of this agent, due to the high milling time, the cold welding process is difficult to be controlled.

Table 1. Particle size obtained after MA process of $\mathrm{Ti}, \mathrm{Nb}$ and $\mathrm{Sn}$ by Laser Scattering.

\begin{tabular}{|llll|}
\hline Particle size & Minimum $(\mu \mathrm{m})$ & Maximum $(\mu \mathrm{m})$ & Average $(\mu \mathrm{m})$ \\
\hline $\mathrm{Ti}$ & 11.06 & 29.23 & 55.93 \\
\hline $\mathrm{Nb}$ & 2.53 & 15.94 & 45.00 \\
\hline $\mathrm{Sn}$ & 6.19 & 16.94 & 52.32 \\
\hline Milled Powder 72 h & 1.86 & 171.47 & 19.12 \\
\hline
\end{tabular}

In part, the agglomerated powders, due to the high milling time, and the greater impact of the powders due to shocks with the vessel balls, can contribute to decrease the porosity, towards a higher density. In addition, longer period of milling can promote morphological changes in the particles, resulting in more spherical particles creation, which are more suitable for the compaction and sintering process.

By the XRD pattern shown in figure 1 , it can be seen the $72 \mathrm{~h}$ of milling resulted a material structured under two phases. Being them: phase a, represented by the compact hexagonal (hcp) structure, formed by a small peak that appears around $35^{\circ}$, characterized by the plane $\{100\}_{a}$ and phase $\beta$, represented by the body centered cubic (bcc) structure. The milling process promoted almost $80 \%$ of $\beta$ phase formation (Table 2), due to the allotropic transformation obtained during the MA, by the diffusion of $\mathrm{Nb}$ atoms in the Ti lattice. The a phase is present, approximately $22 \mathrm{wt} \%$. The quality of the refinement performed, obtained by the weightedprofile R value (Rwp) was satisfactory $(<10 \%)$. The oxygen and nitrogen content was evaluated after the milling process (seen is table 3 ). The values of oxygen content was reasonable in the case of a high milling time compared to Ti-Nb based alloys in the range 1.0-2.5 at.\% [29,30].

Table 2. Quantification of the phases present after the MA process obtained by structural refinement.

\begin{tabular}{|lll|}
\hline Rwp (\%) & a phase (\%) & $\beta$ phase (\%) \\
\hline 5.8 & $22.1 \pm 0.0$ & $77.9 \pm 5.8$ \\
\hline
\end{tabular}

Table 3. $\mathrm{O}$ and $\mathrm{N}$ content in the powders after MA process.

\begin{tabular}{|lll|}
\hline Milled Powder & $0(w t \%)$ & $N(w t \%)$ \\
\hline Ti-34Nb-6Sn & $1.09 \pm 0.04$ & $0.216 \pm 0.08$ \\
\hline
\end{tabular}

Figure 2, referring to the cross section of powders, it is possible to notice after $72 \mathrm{~h}$ of milling, the Ti-34Nb-6Sn structure present a small amount of typical microstructural composite particles, represented by the white board, where the clearest contrast is found, due to the presence of elements with a higher atomic number, in this case $\mathrm{Nb}$, and the darkest contrast indicating zones richest in titanium. No elemental particles (like $\mathrm{Ti}, \mathrm{Nb}$ or Ti) was found. In addition, there is a good homogeneity and uniformity of the microstructure formed. The milling time used, caused a good cracking of the powders, decreasing the surface area of concentration of an element. 
It is more clear to observe two distinct regions present in the microstructure of the material after milling process in figure 3a. The homogeneity of the particles (Figure 3b) is indicated by the map, with good distribution of the three elements ( $\mathrm{Ti}, \mathrm{Nb}$ and $\mathrm{Sn}$ ). These structures of suitable uniformity, resemble a plate, which consists of a fine and homogeneous distribution of the components of the solute in the titanium matrix. The other region, on the other hand, is visible the presence of zones enriched by niobium and titanium that did not react within the milling time, remaining trapped in the microstructure of the material, but are less amount present in the microstrure. From the analysis by EDS (Figure 3c), the components present the percentage reasonable close to the compositional. The second peak present in Figure $3 \mathrm{c}$ is represented by the carbon detected due to the resine used to embbed the samples.

In this case, tin presents $4 \%$ more content than added. This characteristic may be due to the low homogeneity of this element in the regions presented by the map (in green color). However, in general, the MA process promoted good homogeneity of the structure by the milling time used.

The XRD profile of materials sintered via ERS with electrical current density of 11, 12 and $13 \mathrm{kA}$, are shown in figure 4 and were compared wih the XRD profile powders after the MA at the same scale. As can be seen, the XRD patterns are formed by peaks related to the $a^{\prime \prime}-$ martensite and $\beta$ phases in all samples. The orthorhombic phase $a^{\prime \prime}$, presents an elastic modulus smaller than the hexagonal a phase [31], being interesting for orthopedic application. In also figure 4a the typical microstructure obtained by EBSD evaluation show the slight presence of Ti-a (represented in blue) that could not be posible identified by the XRD.

Among the component elements of the alloy, niobium is present in greater proportion, compared to the tin. Besides, niobium has a melting point $\left(2468^{\circ} \mathrm{C}\right)$ higher than tin $\left(231,97^{\circ} \mathrm{C}\right)$. Thus, the diffusion rate is lower compared to tin. Due to the low diffusion rate, homogeneity it is also smaller, creating areas rich in titanium which in turn become orthorhombic phase during the sintering process via ERS. It is noted that obtaining samples with electrical current density at $11 \mathrm{kA}$ promoted more formation of phase a"-martensite, where the peaks are more intense (Figure 4a). This fact proves the difficulty in diffusing niobium, due to the low electrical current used. The energy of the system was lower than 12 and $13 \mathrm{kA}$ to ensure suficient diffusion and thus promoted the formation of the a"-martensite phase, as evidenced by the higher peak intensity. The increase of the electrical current intensity, the peaks referring to the $a^{\prime \prime}$-martensite phase decreased. The greater stabilization of phase $\beta$ can cause the transformation to $\beta^{\prime}$ instead of a"-martensite. However, the presence of $\otimes$ phase by its nanometric size that would require its observation in TEM because it is not posible observed it in XRD. When comparing the XRD profile of the samples at $12 \mathrm{kA}$ and $13 \mathrm{kA}$, no significant differences are observed. Visibly, a difference is observed between the patterns of samples obtained by ERS and powders after MA process. The main differences from the XRD pattern of the powders is the unique presence of phase $\beta$, being mostly Ti- $\beta$ and also niobium particles that present the lattice parameters close to Ti- $\beta$, which makes difficult to distinguish them. Another significant difference is the widening of the Ti$\beta$ phase peaks, related to the $\{110\},\{200\}$ and $\{211\}$ plans present in the powders' XRD profile. The larger peaks and their electrical lower intensities are due to the milling time used, the high refinement of the niobium grains and the micro-deformation inside these grains [32]. According to Fecht, it was found that grain refinement and micro-deformation increase during the milling [33]. Besides, increasing the milling time, the 
particles are increasingly refined. In the work of Zhang et al., the effect of milling nioium, titanium and silicon powders was evaluated at 2, 5, 10, 20 and $40 \mathrm{~h}$. After $20 \mathrm{~h}$ the peaks became wider and less intense [34].

The mechanical milling in significantly long times increases beyond the local deformations in shear strips, with high displacement densities at the beginning of the refinement process. These displacements combine among themselves creating grain limits formation of low angle [35]. These small limits of formed grains are transformed into grain limits at a greater angle, producing more refinement particles. In addition, the microdeformation increases, during the press balls in MA, along with the particles, collide continuously and irreversible deformations increase leading to micro-deformation.

In figure $4 \mathrm{~b}$ it is possible to see the largest widening of the peak of the $\beta$ phase represented by the $\{110\}$ plane in the powder pattern. The increase in the electrical current density used, the widening decreases and increases the peak intensity. The main reason for the widening of the peak may be due to the accumulation of defects in the lattice produced during the milling [36], as displacements and point defects, promoting the vacant site formation in the crystalline lattice or by compression of an atom present in an interstitial site in the crystalline lattice. Figure 4B also shows a displacement of the sample peaks at 11 and $13 \mathrm{kA}$ at angles more intenses. The peak referring to the sample made at $12 \mathrm{kA}$, on the other hand, promoted a displacement at lower angles.

This effect is due to a variation in the distances $d$ from the plane of the crystallographic lattice. For values of $(2 \theta)_{\text {final }}<(2 \theta)_{\text {incial, }}$, as in the case of the peak referring to the sample obtained at $12 \mathrm{kA}\left(2 \theta \cong 38.5^{\circ}\right)$, the values increased during sintering, respecting the Bragg equation $(2 \mathrm{ddin}(\theta)=\lambda \mathrm{n})$

Figure 4. Structural study in the central zone of the samples. a) XRD pattern of powders after MA for $72 \mathrm{~h}$ and EBSD contrast phase micrographs in the central zone of the samples b) Bragg reflections Profiles of the peak of $\beta$ phase represented by the $\{110\}$ plane of milled Ti-34Nb-6Sn and sintered at 11,12 and $13 \mathrm{kA}$ by ERS.

In table 4 shows the parameters obtained of the linear fit of powders after $72 \mathrm{~h}$ of milling time and the sintered samples by ERS. Figure 5a-d shows the best fitted linear plots between the powders milled and samples sintered with 11, 12 and $13 \mathrm{kA}$ respectively. Crystallites size (D) were calculated from the intercept cut on y axis (represented by $\beta \cos \theta$ ) while lattice strain $(\varepsilon)$ was determined by the slope of the fitted straight line using Wlliamson Hall equation [27]. In order to compare the evolution of crystallite size and residual stresses after material consolidation via ERS.

The level of deformation experienced by the lattice was evaluated analyzing their corresponding crystallite size and residual micro-strains indicated in table 5 . In the present study, the crystallite size increased significantly after consolidation process of the Ti-34Nb-6Sn alloy compared to the initial value obtained during the MA. The deformation mechanism that dominant in the ball milling process is the formation of shear bands which have high dislocations density due to the constant impact associated with the powder particles on the balls as discussed. The high milling time used, fragmentation of the sub-grains occurs from the region where unstrained shear band present in the previous material. Due to grain cracking, the degree of randomness of the sub-grains orientation increases. The grain size reduction occurs till the complete random orientation of the sub-grains obtained [37]. It is evident that the sintering temperature contributed to the 
significant increase the crystallite size in all conditions. However, in the condition of lower electrical current density $(11 \mathrm{kA})$, there is evidence it promoted a greater number of defects introduced in the microstructure [38], since the crystallite size is significantly higher in this condition. While decreasing with increasing electrical current density. Likewise, the sintered samples at 11 and $12 \mathrm{kA}$ showed a decreasing trend of the lattice strain, compared to the sample of milled powders. However, at an electrical current density of $13 \mathrm{kA}$, the value increased again, with a value close to that obtained after milling process. In this condition, there was a high level of material transfer and the diffusion process was more accelerated induced by the high electrical current density used, at the same time of consolidation than the others. In this way, the plasma creation between the particles contributed to the fast consolidation of the material along with the Joule effect and plastic deformation as a result of compaction in the ERS technique. According to Singh et al., the high concentration of defects is produced during the densification of the samples by the rapid heating and associated with the rapid deformation of the particles [39]. This defect formation is aided by the high electrical current used essential to generate the heating. Kim et al., and Besson \& Abouaf, found that this defect induced by the deformation is responsible for the dynamic growth of the grains $[40,41]$.

Some researchers have reported that the higher heating rate, the diffusion process of grain contour is driven by very substantial stresses (inversely proportional to the radius of curvature of the pore), since diffusion on the surface does not have enough time to "smooth" pore surfaces [42]. At the same time, due to densification, the pore size decreases significantly, which prevents them from exerting the fixation effect. For grain growth to occur, the sintering time must be long enough than this critical point. But, for high heating rates, grain growth is slowed due to shorter processing time. In this present work, the heating time was constant, only the current density being varied. However, the mechanism of densification and diffusion are the same, since with the increase of the electrical current density, the system energy increases, consequently increasing the heating temperature. Thus, even with the high temperature provided by the increase in electrical current density, the time was not enough to promote an increase in the crystal size, but promoted a decreasing of $17 \%$.

Table 4. Parameters obtained of the multiple peaks fit analysis. 


\begin{tabular}{|lll|}
\hline Samples & FWHM $=\beta$ & Height \\
\hline Powders obtained by MA & 1.11 & 2438 \\
& 1.51 & 126 \\
\hline $11 \mathrm{kA}$ & 1.68 & 321 \\
& 0.46 & 613 \\
& 0.42 & 517 \\
\hline 12kA & 0.36 & 490 \\
\hline & 0.29 & 12856 \\
\hline 13kA & 0.36 & 1252 \\
\hline & 0.40 & 1966 \\
\hline & 0.42 & 1413 \\
\hline & 0.44 & 1711 \\
\hline
\end{tabular}

Table 5. Variation of crystallite size (D) and lattice strain $(\varepsilon)$ for Ti-34Nb-6Sn milled powders and sintered samples via ERS.

\begin{tabular}{|c|c|c|}
\hline Samples & $\varepsilon(\%$ Strain $)$ & $\mathrm{D}$ (crystallite size, $\mathrm{nm}$ ) \\
\hline Powders obtained by MA & 5.5 & 16.51 \\
\hline $11 \mathrm{kA}$ & 3.0 & 274.02 \\
\hline $12 \mathrm{kA}$ & 3.2 & 183.40 \\
\hline $13 \mathrm{kA}$ & 5.3 & 152.37 \\
\hline
\end{tabular}

The powders prepared by MA after $72 \mathrm{~h}$, was consolidated via ERS. The first sintering was using an electric current density of $11 \mathrm{kA}$, represented by figure 6a-c. The current used, promoted an advance in the alloy consolidation. It is noted that in the peripheral region, the material was poorly sintered, confirmed by the presence of microporosities in the microstructure (Figure 6a). In these regions there was less heat distribution, as the presence of solute (niobium particles) that has not just diffused into the titanium matrix is still noticeable (Figure 6b). By line analysis (Figure 6c), the lack of uniformity in the peripheral region of the material is confirmed. The tin element seems to be well dissolved in the titanium matrix, due to the linearity presented by its curve. The niobium, on the other hand, when entering the brightest contrast regions, increases its intensity abruptly. This abrupt transition between the elements indicates a transient diffusion of them, which some reach approximately $2.5 \mu \mathrm{m}$, resulting from the lack of heat obtained by the system.

Figure 7 shows the process of low sintering in the peripheral region persists at $12 \mathrm{kA}$ (Figure 7a), due to the presence of microporosities and also due to the presence of solute particles unsoluble. However, there is an improvement in the uniformity of the material. There are enriched regions of niobium, (Figure 7b) but fewer 
regions where particles are found completely unreacted. Going to places located in the center of the material (Figure 7c), it is noticed that there are practically no solute particles. This shows the heat distribution by the current of $12 \mathrm{kA}$ used was more efficient for the alloy consolidation.

As in figures 6 and 7, figure 8a-c, indicated that the $13 \mathrm{kA}$ electrical current also promoted the microporosity, possibly due to the low sintering in the regions most distant from the central zone of the material (Figure 8ab). In the central zone, as in other cases, practically all the material is melted (Figure 8c). The presence of nanopores in the central zone of the sample (more melted) were found. The abundant presence of nanopores is related as a result of the fusion and blocking of the gas escape during solidification by the sealing of the surface that is caused by the increase in electrical current density.

In the EBSD-IPF-Z images contained in figure 9a-c, the distribution of grains formed after consolidation of the Ti-34Nb-6Sn alloy by ERS of the central regions are represented. The images were obtained by the cross sections of the materials metallographically prepared. In figure 9a, the consolidated alloy with an electrical current intensity of $11 \mathrm{kA}$, presented a microstructure with colonies of bcc- $\beta$ grains equiaxial of solid titanium solution ( $\mathrm{Nb}, \mathrm{Sn}$ ), with equivalent circle diameter $(\mathrm{ECD})$ of $0.75 \mu \mathrm{m} \pm 0.36 \mu \mathrm{m}$. The grains also presented good homogeneity. By increasing the electrical current intensity to $12 \mathrm{kA}$, the predominance of $\beta$ grains was again noticed, with ECD of $1.01 \mu \mathrm{m} \pm 0.55 \mu \mathrm{m}$ (Figure 9b). The intensity of $12 \mathrm{kA}$ promoted, both grain growth, and decreased in size homogeneity. The grains morphology in figures $9 a$ and $b$ are similar, differing basically in the size of the formed colonies. In figure $9 \mathrm{c}$, it indicates the microstructure of the material sintered at $13 \mathrm{kA}$. There is a significant variation in the size of $\beta$ grains with minimum around of $10 \mu \mathrm{m}$ and maximum around of $166 \mu \mathrm{m}$ grain size with ECD of $28.14 \mu \mathrm{m} \pm 26.86 \mu \mathrm{m}$. This difference both in size and homogeneity of the microstructure can be associated with a grain growth by the high energy available with the greater intensity of current that nevertheless leaves areas where these grains have not yet grown (observation of the different magnification used). It is clear that increasing electrical current intensity, the microstructure becomes less uniform.

In table 6 , the percentages of phase obtained by the EBSD analysis indicate a predominant phase $\beta$ formation, being higher than $95 \%$ in all conditions. In the sintering at $11 \mathrm{kA}$, the percentage of $\beta$ phase is smaller than at $12 \mathrm{kA}$ and $13 \mathrm{kA}$. In this condition, has more pixels without indexing, which is evident is the decrease in the small amount of a phase determined, due to the lower amount of residual titanium non-diffusing. The $\beta$ phase at $12 \mathrm{kA}$ has an increase in relation to the lower electrical current intensity used of $1.6 \%$. The $\beta$ phase at $13 \mathrm{kA}$, it was higher at around $5 \%$ compared to samples obtained at 11 kA. The percentage of $\beta$ phase also confirms the microstructure shown in figure 9 , predominantly formed by bcc- $\beta$ equiaxis grains. It is also noted that with the increase of the electrical current intensity, the a"-Ti phase decreased as well as the $a-T i$ phase. As studied by Gouvea et al., the same growth trend of $\beta$ grains was observed, by increasing the electric current from $14 \mathrm{kA}$ to $16 \mathrm{kA}$, in addition to the bimodal distribution of grains in a higher current intensity ( $16 \mathrm{kA})$ [43]. In our case, the process also occurred at a higher electrical current (13 kA), however, less than they used at work, to pruduce samples with $16 \mathrm{~mm}$ diameter compressed at $50 \mathrm{MPa}$. The possibility to increase the grain size early, may be due to the lower content of $\beta$ phase stabilizer element used, and the longer milling time. In their work, were used niobium and molybdenum as $\beta$ phase stabilizers. 
Table 6. Percentage of phases analyzed by EBSD at the different sintering current intensities, after consolidation of Ti-34Nb-6Sn via ERS.

\begin{tabular}{|llll|}
\hline Intensity Current (kA) & Phase Name & Phase Fraction (\%) & Phase Count \\
& & & \\
\hline 11 & Titanium cubic & 96.56 & 36127 \\
\cline { 2 - 4 } & Ti-Hex & 0.27 & 101 \\
\cline { 2 - 4 } & Ti-alfa2prima & 3.17 & 1187 \\
& Titanium cubic & 98.12 & 153313 \\
\hline 13 & Ti-Hex & 0.09 & 144 \\
\cline { 2 - 4 } & Ti-alfa2prima & 1.79 & 2792 \\
\hline & Titanium cubic & 98.02 & 105540 \\
\cline { 2 - 4 } & Ti-Hex & 0.03 & 38 \\
\hline & Ti-alfa2prima & 1.95 & 2105 \\
\hline
\end{tabular}

The microhardness was measured in the cross sections of the samples, in order to obtain more reliable results of the different conditions. In addition, due to the greater homogeneity of the microstructure of the central region of the samples via ERS, measures were taken in this region. According to table 7, the microhardness decreases with the increase of the electrical current intensity, where the content of a" orthorrombic phase decreases and also a growth of the grains. In the work of Amigó-Mata et al., were studied Ti-6Al-4V and Ti-CP consolidated via ERS in 10 and $12 \mathrm{kA}$. The materials presented slight decrease in microhardness when increase the current intensities [44]. The decrease in hardness may be related to the rapid sintering of the materials, reducing the oxidation. In the work of $\mathrm{Li}$ et al., as-cast Ti-Nb-Sn alloys with different compositions were studied. The hardness values found ranged from $346.7 \mathrm{HV}-265 \mathrm{HV}$ [45] It is lower than in the present study. In the work of Utomo et al., the influence of the element Sn on the microhardness of the Ti-Nb-Sn system was studied. The Ti-30Nb-2Sn, Ti-30Nb-5Sn and Ti-30Nb-8Sn alloys showed hardness values of 473, 455 and 559 HV (as-cast) [46]. In this case, the hardness was greater in all cases compared to those found in the present study. The hardness value depends on several factors, such as the composition of the alloy, the microstructure and the surface conditions and also the type of processing used to obtain the samples. Comparing with Ti-CP and Ti-6Al-4V alloys that present hardness values around $200 \mathrm{HV}$ and $340 \mathrm{HV}$ [47], the values found are much higher.

Table 7. Microhardness of Ti-34Nb-6Sn alloy after consolidation via ERS. 


\begin{tabular}{|ll|}
\hline Condition & $\begin{array}{l}\text { Microhardness } \\
(\mathrm{HV})\end{array}$ \\
\hline $11 \mathrm{kA}$ & $418.65 \pm 18.82$ \\
\hline $12 \mathrm{kA}$ & $404.25 \pm 26.06$ \\
\hline $13 \mathrm{kA}$ & $389.25 \pm 21.53$ \\
\hline
\end{tabular}

Figure 10a-b) shows the OCPs versus time curves of sintered samples at 11, 12 and $13 \mathrm{kA}$ in Ringer Hartmann's solution at $37^{\circ} \mathrm{C}$. The curves of each material after immediate immersion in the solution, (close to $5 \mathrm{~min}$ ) increase the potential rapidly, at noble potential values (Figure 10a) that evidence the growth of a protective passive film. The figure 10b, shows the details of OCP values during last $10 \mathrm{~min}$. The sample obtained under $11 \mathrm{kA}$ condition presented stable OCP at $-0.06 \mathrm{~V}$ and remained stable throughout the experimental time. The $12 \mathrm{kA}$ condition, the curves showed a more noble potential than the $11 \mathrm{kA}$, with a value of $-0.04 \mathrm{~V}$, as well as in the condition at $11 \mathrm{kA}$, remaining constant during the analysis time. The condition at $13 \mathrm{kA}$ had the lowest $\mathrm{OCP}$, with a value of $-0.08 \mathrm{~V}$.

This process occurs in different potential ranges due to the heterogeneity.

However, the potentiodynamic polarization curves (PPCs) (see Figure 11) show the samples obtained at 11 and $12 \mathrm{kA}$ exhibit lower corrosion current density $\left(\mathrm{i}_{\text {corr }}\right)$ and higher corrosion potential $\left(\mathrm{E}_{\text {corr }}\right)$. Figure 11 also shows regions characterized by an almost constant current density, indicated between dashed lines. The oxidation rate decreases due to a protection effect of passive layer formed on the sample surfaces during active state. The passive layer grows as the materials are polarized till a further increase in the current intensity is observed that indicates the transpassive process starts. This current increase at transpassive region was related to the oxygen evolution the electrode or/and a pitting corrosion, an intense oxidation and dissolution in the isolated points on the unshielded passive metal surface. This process occurs in diferent potential ranges due to the heterogeneity of the microstructure. The estimated corrosion potential $\left(\mathrm{E}_{\text {corr }}\right)$ of the curves for the sintered alloy at $11 \mathrm{kA}$ was $-0.43 \mathrm{~V} \pm 0.13 \mathrm{~V}$, at $12 \mathrm{kA}$ from $-0.40 \mathrm{~V} \pm 0.09 \mathrm{~V}$ and at $13 \mathrm{kA}$ from $-0.47 \mathrm{~V} \pm 0.015 \mathrm{~V}$. As found in the OCP curves, Ecorr showed the same tendency to increase with the increase in sintering electrical current density at $12 \mathrm{kA}$ and to decrease with the increase of $13 \mathrm{kA}$, which promoted less uniformity in grain sizes. According to Afonso et al., was demonstrated the correlation between hardness, $\mathrm{E}_{\text {corr }}$ and niobium content of the Nb-Ni binary systems solidified [48]. It was evident that hardness and $\mathrm{E}_{\text {corr }}$ are inversely proportional parameters. This fact can be observed in the present work, since the hardness decreased when the current intensity increased from $11 \mathrm{kA}$ to $12 \mathrm{kA}$, the $E_{\text {corr }}$ value increased. However, for sample obtained at $13 \mathrm{kA}$, the hardness value was smaller than obtained at 11 and $12 \mathrm{kA}$, but $\mathrm{E}_{\text {corr }}$ decreased significantly. Possibly this fact can be attributed to a non-uniformity of the microstructure, confirmed by the heterogeneity of the grain sizes.

These potentials obtained (Table 8 ) by the polarization curves were significantly lower than those obtained from the OCP measurements, because the polarization test was started at a cathodic potential and in this way the passive oxide film on the surface was partially removed due to the cathodic polarization. 
The polarization resistance followed the same trend as the $\mathrm{E}_{\text {corr }}$ values to inherit at 11 and $12 \mathrm{kA}$, altered a decrease in $R_{p}$. In the condition at $13 \mathrm{kA}$, the $\mathrm{R}_{\mathrm{p}}$ increases significantly. However, this increase can be explained by the lack of microstructural homogeneity. Figure 11 shows regions characterized by an almost constant current density, starting where indicated by the dashed lines. This region indicates the formation and growth of a passive film on the surface of the samples. In the conditions at 11 and $13 \mathrm{kA}$ it is noted that the passivation process starts at a potential close to $1.7 \mathrm{~V}$ and for the material obtained at $12 \mathrm{kA}$, start of passivation was close to $1.8 \mathrm{~V}$, demonstrating a later passivation. This can be confirmed by the corrosion resistance paremeter, $\mathrm{Cr}$, obtained by the use of $\mathrm{i}_{\text {corr }}$ of each sample (see Table 8 ).

In the work of Mavros et al., the Ti-Nb-Zr-Ta alloy ssystem was obtained for biomedical application by the SPS technique, with good resistance to corrosion. The excellent corrosion resistance of $\beta$-type alloys formed by refractory elements such as niobium, can contribute to the formation of a passive film layer that is not released into the environment [49]. In addition, this oxide layer formed on the surface of titanium alloys, as well as its composition, affects the corrosion response of these alloys when used to manufacture orthopedic prostheses [6].

The corrosion current density found for this type of alloy is in the range of 0.4 to $0.7 \mu \mathrm{A} / \mathrm{cm}^{2}$. It is worth mentioning that the solution used was $\mathrm{NaCl}$, which has an ionic concentration and $\mathrm{pH}$ different from those present in the body fluid. Alloys of the Ti-Nb-Zr system obtained also by SPS showed a much higher corrosion current density value compared to the present work, being $2.42 \mu \mathrm{A} / \mathrm{cm}^{2}$ for the Ti-13Nb-13Zr alloy. Regarding commercially pure $\mathrm{Ti}$, one of the most used materials in the biomedical sector, $\mathrm{I}_{\text {corr }}$ is approximately $3 \mu \mathrm{A} \mathrm{cm}{ }^{2}$ [50], significantly higher than the values found for the Ti-34Nb-6Sn alloy in all conditions in the present work.

Figure 11. PPC curves of the Ti-34Nb-6Sn alloy obtained by the potentiodynamic test carried out under the different experimental conditions obtained via ERS.

Table 8. Kinetic parameters obtained from anodic curves by the potentiodynamic test.

\begin{tabular}{|lllll|}
\hline Condition & $\mathrm{i}_{\text {corr }}\left(\mu \mathrm{A} / \mathrm{cm}^{2}\right)$ & $\mathrm{E}_{\text {corr }}(\mathrm{V})$ & $\mathrm{R}_{\mathrm{p}}(\mathrm{K} \Omega)$ & $\mathrm{C}_{\mathrm{r}}(\mu \mathrm{m} /$ year $)$ \\
\hline $11 \mathrm{kA}$ & $0.38 \pm 0.25$ & $-0.43 \pm 0.13$ & $84.4 \pm 55.63$ & 2.67 \\
\hline $12 \mathrm{kA}$ & $0.45 \pm 0.06$ & $-0.40 \pm 0.09$ & $56.2 \pm 8.21$ & 3.16 \\
$13 \mathrm{kA}$ & $0.24 \pm 0.01$ & $-0.47 \pm 0.15$ & $111 \pm 29.44$ & 1.68 \\
\hline
\end{tabular}

In figure 12 are indicated the Nyquist diagrams of the EIS experiments in the samples sintered at 11,12 and 13kA. For the obtained EIS data were modelled on the basis of the CPE circuit shown in the inset of the figure 12. The best fitting (Goodness of fit, seen in table 9) was provided using the equivalent circuit of Rs (CPEdl Rct) for all samples. In the equivalent circuit, Rs and Rct referred to the solution resistance and circuit resistance. Another variable employed to describe passive layers, ndl, is the coefficient of CPEdl, which is the interfase CPEdl and the electrolyte and transfer charge resistance related to Cdl (Eq. 2). The Cdl parameter of the samples was calculate according to following equation and are present in the table 9. 


$$
C d l=\left(\frac{C P E d l}{\left(R s^{-1}+R c t^{-1}\right)^{1-n d l}}\right)^{1-n d l}
$$

The impedance spectra of three samples present diferent characteristics. The first one (at $11 \mathrm{kA}$ ) show characteristics of half capacitive arc resistance. The impedance spectrum radius is larger compared to the others samples, showing higher corrosion resistance. The second and third samples (at 12kA and 13kA) show Nyquist spectra similar to the semicircular arc. This characteristic is present in passive metals, or capacitor [51]. Moreover, the end of the semicircle of the second and third samples plot reached $700 \Omega$ and $94 \Omega$ on the x-axis. In the first sample, obtained at $11 \mathrm{kA}$ the half capacitive arc reached $1175 \Omega$ on the x-axis.

The Rs values of the samples obtained at 12 and $13 \mathrm{kA}$ were similar, while at $11 \mathrm{kA}$ the Rs was lower (\%). The Rct in all samples were higher compared to the Rs values. The $11 \mathrm{kA}$ showed the highest value, followed by the sample obtained at $13 \mathrm{kA}$ and finally at $12 \mathrm{kA}$. The high Rct value is associated with good corrosion resistance. It has already been established that the high density of grain boundaries in metals with nano-size grains improves the production of a passive layer on the metallic surface [52], which further enhances the corrosion resistance through restraint of the interaction between metals in an aggressive situation. The $\mathrm{Ti}-\mathrm{Nb}$ Sn samples obtained a lower eletrical current density suggests that some defects, permit aggressive species to find solutions and creating susceptibility to corrosion on titanium. Hence, the higher Rct and the lower Qdl values observed in sample produced at 13kA indicate a nobler electrochemical performance, which is in good agreement with the potentiodynamic polarization results.

Figure 12. Typical Nyquist diagram for tested samples and the equivalente electric circuit for EIS data analysis (Rs-solution resistance, Rct- circuit resistance, CPEdl-constant phase element (non-ideal capacitance).

Table 9. Parameters calculated from electrochemical impedance spectroscopy (EIS) measurements.

\begin{tabular}{|lllllll|}
\hline Condition & $\begin{array}{l}\text { Goodness } \\
\text { of Fit }\end{array}$ & Rs & CPEdl-T & ndlCPEdlP & Rct & Cdl $\left(\mu \mathrm{F} / \mathrm{cm}^{2}\right)$ \\
\hline $11 \mathrm{kA}$ & 0.00334 & $28.95 \pm 0.27$ & $2.28 \times 10^{5} \pm 7.22 \times 10^{7}$ & $0.92 \pm 0.00$ & $3318 \pm 142$ & 11.90 \\
\hline $12 \mathrm{kA}$ & 0.000665 & $37.24 \pm 0.44$ & $7.97 \times 10^{-5} \pm 1.07 \times 10^{5}$ & $0.74 \pm 0.02$ & $71.85 \pm 2.43$ & 10.23 \\
\hline $13 \mathrm{kA}$ & 0.00365 & $37.09 \pm 0.51$ & $7.09 \times 10^{-5} \pm 5.43 \times 10^{6}$ & $0.73 \pm 0.01$ & $556 \pm 24.73$ & 8.29 \\
\hline
\end{tabular}

\section{Conclusions}

Ti-Nb-Sn system with $34 \mathrm{wt} \%(\mathrm{Nb})$ and $6 \mathrm{wt} \%(\mathrm{Sn})$ was obtained by electrical resistance sintering (ERS) process at 11, 12 and 13kA of electrical current density. The effect of current in the microstructure was evaluated. The main conclusions are highlighted above:

- The samples are structured under $a, a^{\prime \prime}$ and phase $\beta$. Increasing the electrical current density, the phase $\beta$ increased to values around to $98 \%$; 
- The samples obtained at 12kA presented good homogeneity of the microstructure (less micro and nanoporosity and also less presence of particles unsoluble);

- The microstrucutre are formed by bcc- $\beta$ grains equiaxial, with the grain size more uniforme in the samples obtained at 11 and $12 \mathrm{kA}$;

- The microhardness decreased with the increase in electrical current density, and the values are in the range of 389-418 HV;

- Corrosion tests proved excellent corrosion resistance of the alloys with low current densities, despite presence of micro and nanoporosity.

- The corrosion rate in all cases are very low, but the standard deviation are very higher in the samples obtained at 13kA, related to the lack of uniformity of the microstructure;

\section{Declarations}

Funding (This work was supported by the Fundação de Amparo à Pesquisa do Estado de São Paulo (FAPESP) [grant: 2019/24237-6]; Ministerio de Economía y Competitividad de España for the research project RTI2018-097810-B-I00 and the European Commission throught FEDER).

Acknowledgment (The authors thank the AMES Company for the materials development).

Conflicts of interest (The authors declare that they have no known competing financial interests or personal relationships that could have appeared to influence the work reported in this paper).

\section{Availability of data and material (Not applicable)}

Code availability (Not applicable)

Authors' contributions (Conceptualization: [Mariana Correa Rossi], Methodology: [Mariana Correa Rossi], Formal analysis and investigation: [Mariana Correa Rossi], [Vicente Amigó Borrás]; Writing - original draft preparation: [Mariana Correa Rossi]; Writing - review and editing: [Margarida Saeki],[Vicente Amigó Borrás]; Data acquisition [Eber de Santi Gouvêa], [Montserrat Vicenta Haro Rodríguez], [Angel Vicente Escuder] Funding acquisition: [Mariana Correa Rossi],[Vicente Amigó Borrás]; Supervision: [Vicente Amigó Borrás]).

\section{References}

1. N. Eliaz, Corrosion of Metallic Biomaterials: A Review. Mater. 12, 407 (2019). https://doi:10.3390/ma12030407.

2. E. J. Evans, Cell damage in vitro following direct contact with fine particles of titanium, titanium alloy and cobalt-chrome-molybdenum alloy. Biomaterials. 442, 713-717 (1994). https://doi.org/10.1016/01429612(94)90170-8.

3. J.E. Bowerman, B. Conroy, A universal kit in titanium for immediate replacement of the resected mandible. J. Oral. Surg. 6, 223-228 (1969). https://doi:10.1016/s0007-117x(68)80041-1. 
4. D.G. Barceloux, Vanadium, J. Toxicol. Clin. Toxicol. 37, 265-278 (1999). https://doi: 10.1081/clt100102425.

5. J.K. Marquis, Aluminum neurotoxicity: an experimental perspective, Bull. Environ. Contam. Toxicol. 29, 43-49 (1982). https://doi: 10.1007/BF01606087.

6. M. Long, H.J. Rack, Titanium alloys in total joint replacement-a materials science perspective. Biomaterials. 19, 1621-1639 (1998). https://doi.org/10.1016/S0142-9612(97)00146-4.

7. M. Niinomi, Mechanical properties of biomedical titanium alloys. Mater. Sci. Eng. A. 3, 231-236 (1998). https://doi.org/10.1016/j.actbio.2006.11.002.

8. H. Kroger, P. Venesmaa, J. Jurvelin, H. Miettinen, O. Suomalainen, E. Alhava, Bone density at the proximal femur after total hip arthroplasty. Clin. Orthop. Relat. 66-74 (1998).

9. T. Ozaki, H. Matsumoto, S. Watanabe, S. Hanada, Beta Ti Alloys with Low Young's Modulus, Mater. Trans. 45, 2776-2779 (2004). https://doi.org/10.2320/matertrans.45.2776.

10. I.J. POLMEAR, Overview: Recent Developments in Light Alloys. Mater. Trans. 37, 12-31 (1996). https://doi.org/10.2320/matertrans1989.37.12.

11. J.L. Murray, The Nb-Ti (Niobium-Titanium) System. Phase Diagr. 2, 55-61 (1981).

12. L. Zhu, Q Zhang, Z. Chen, W. Changdong, C. Ge-Mei, J. Liang, J. Zhanpeng, Z. Ji-Cheng, Measurement of interdiffusion and impurity diffusion coefficients in the bcc phase of the Ti-X (X = Cr, Hf, Mo, Nb, V, Zr) binary systems using diffusion multiples, J. Mater. Sci. 52, 3255-3268 (2017). https://doi 10.1007/s10853-016-0614-0.

13. B. Sharma, S.K. Vajpai, K. Ameyama, Synthesis of Ternary Ti-25Nb-11Sn Alloy by Powder Metallurgy Route Using Titanium Hydride Powder, Mater. Trans. 57, 1440-1446 (2016). https://doi:10.2320/matertrans.mh201510.

14. M.S. Yahaya, M. Sulaiman, N.H.N.E. Azham Shah, M.H. Ismail, Microstructures and Mechanical Properties of Ti-Nb Alloy at Different Composition of Nb Produced via Powder Metallurgy Route, Mater. Sci. Forum. 863, 14-18 (2016). https://doi.org/10.4028/www.scientific.net/MSF.863.14.

15. J. Lux, Improved manufacture of electric incandescence lamp laments from tungsten or molybdenum or an alloy thereof. GB Patent. 1906.

16. G.F. Taylor, Apparatus for Making Hard Metal Compositions. U.S. Patent 1,896,854, 7 February 1933.

17. F.V. Lenel, Resistance Sintering Under Pressure. J Alloy Compd. 7, 158-167. (1955) https://doi.org/10.1007/BF03377473.

18. T.L. Istomina, A.A. Baidenko, A.I. Raichenko, M.A. Goldberg, A.V. Svechkov, Influence of premolding pressure in electric-discharge sintering on the physicomechanical properties of a copper-tin-abrasive composite. Sov. Powder Metal. Met. Ceram. 22, 957-960 (1983). https://doi.org/10.1007/BF00805559.

19. G.L. Burenkov, A.I. Raichenko, M. Suraeva, Dynamics of interparticle reactions in spherical metal powders during electric sintering. Sov. Powder Metall. Met. Ceram. 26, 709-712 (1987). https://doi.org/10.1007/BF00797175.

20. S. Grasso, Y. Sakka, G. Maizza, Electric current activated/assisted sintering (ECAS): a review of patents. 1906-2008. Sci. Technol. Adv. Mater. 10, 053001(2009). 
21. R. Orrù, R. Licheri, A.M. Locci, A. Cincotti, G. Cao, Consolidation/synthesis of materials by electric current activated/assisted sintering. Mat. Sci. Eng. R Rep. 63, 127-287

(2009). https://doi.org/10.1016/j.mser.2008.09.003.

22. E.A. Olevsky, D.V. Dudina, Field-Assisted Sintering Science and Applications, first ed., Cham, Switzerland, 2018.

23. A. Fais, A Faster FAST: Electro-Sinter-Forging, Metal Powder Rep. 73, 80-86 (2018). https://doi.org/10.1016/j.mprp.2017.06.001.

24. E. Cannella, C.V. Nielsen, N. Bay, Process Investigation and Mechanical Properties of Electro Sinter Forged (ESF) Titanium Discs. Int. J. Adv. Manuf. Technol. 104, 1985-1998

(2019). https://doi.org/10.1007/s00170-019-03972-z.

25. U. Anselmi-Tamburini, J.R. Groza, Critical assessment: Electrical field/current application. A revolution in materials processing/sintering. Mater. Sci. Technol. 33, 1855-1862 (2017) https://doi.org/10.1080/02670836.2017.1341692.

26. M.A. Lagos, I. Agote, T. Schubert, T. Weissgaerber, J.M. Gallardo, J.M. Montes, L. Prakash, C. Andreouli, V. Oikonomou, D. Lopez, J.A. Calero, Development of electric resistance sintering process for the fabrication of hard metals: Processing, microstructure and mechanical properties. abbreviations: Int J Refract Metals Hard Mater. 66, 88-94 (2017). https://doi:10.1016/j.ijrmhm.2017.03.005.

27. G.K. Williamson, W.H. Hall, X-ray line broadening from filed aluminium and wolfram, Acta Metall. 1, 22-31 (1953). https://doi.org/10.1016/0001-6160(53)90006-6.

28. A.M. Soufiani, F. Karimzadeh, M. Enayati, Formation mechanism and characterization of nanostructured Ti6Al4V alloy prepared by mechanical alloying, Mater. Des. 37, 152-160 (2012). https://doi.org/10.1016/j.matdes.2011.12.044.

29. L.M. Zou, C. Yang, Y. Long, Z.Y. Xiao, Y.Y. Li, Fabrication of Biomedical Ti-35Nb-7Zr-5Ta Alloys by Mechanical Alloying and Spark Plasma Sintering. Powder Metall. 55, 65-70 (2012). https://doi.org/10.1179/1743290111Y.0000000021.

30. J. Málek, F. Hnilica, J. Veselý, B. Smola, Heat Treatment and Mechanical Properties of Powder Metallurgy Processed Ti-35.5 Nb-57Ta Beta-Titanium Alloy. Mater. Charact. 84, 225231(2013). https://doi.org/10.1016/j.matchar.2013.08.006.

31. C.M. Lee, C.P. Ju, J.H.C. Lin, Structure property relationship of cast Ti-Nb alloys. J. Oral Rehabil. 29, 314322 (2002). https://doi:10.1046/j.1365-2842.2002.00825.x.

32. C. Slama, M. Abdellaoui, Microstructure characterization of nanocrystalline (Ti0.9W0.1) C prepared by mechanical alloying. Int. J. Refract. Met. Hard Mater. 54, 270-278 (2016). https://doi.org/10.1016/j.ijrmhm.2015.07.018.

33. H.J. Fecht, Nanostructure formation by mechanical attrition. Nanostruct. Mater. 6, 33-42 (1995).

34. L. Zhang, X. Guo, Microstructural Evolution, Thermal Stability and Microhardness of the Nb-Ti-Si-Based Alloy during Mechanical Alloying. J. Met. 8, 403 (2018). https://doi:10.3390/met8060403.

35. A.F. Mohamed, A dislocation model for the minimum grain size obtainable by milling, Acta Mater. 51, 4107-4119 (2003). https://doi:10.1016/s1359-6454(03)00230-1. 
36. K.V. Sanjay, A. Kei, A novel powder metallurgy processing approach to prepare fine-grained Ti rich TiAlbased alloys from pre-alloyed powders. J. Intermet. 42 146-155

(2013). https://doi.org/10.1016/j.intermet.2013.06.006.

37. P. Singh, A. Abhash, B.N. Yadav, M. Shafeeq, I.B. Singh, D.P. Mondal. Effect of milling time on powder characteristics and mechanical performance of Ti4wt\%Al alloy. Powder Technol. 342, 275-287 (2018). https://doi:10.1016/j.powtec.2018.09.075.

38. A. Khorsand Zak, W.H. Abd Majid, M.E. Abrishami, R. Yousefi, Solid State Sci. 13, 251 (2011). https://doi.org/10.1016/j.solidstatesciences.2010.11.024.

39. L.K. Singh, A. Bhadauria, S. Jana, T. Laha, Effect of Sintering Temperature and Heating Rate on Crystallite Size, Densification Behaviour and Mechanical Properties of Al-MWCNT Nanocomposite Consolidated via Spark Plasma Sintering. Acta Metall Sin-Engl. 31, 1019-1030 (2018). https://doi:10.1007/s40195-018-0795-4.

40. B.N. Kim, K. Hiraga, K. Morita, H. Yoshida, Y.J. Park, Y. Sakka, Dynamic grain growth during lowtemperature spark plasma sintering of alumina. Scr. Mater. 80, 29-32 (2014) https://doi.org/10.1016/j.scriptamat.2014.02.015.

41. J. Besson, M. Abouaf, Grain growth enhancement in alumina during hot isostatic pressing. Acta Metall. Mater. 39, 2225-2234 (1991). https://doi.org/10.1016/0956-7151(91)90004-K.

42. E.A. Olevsky, S. Kandukuri, L. Froyen, Consolidation enhancement in spark-plasma sintering: Impact of high heating rates, J. Appl. Phys. 102, 114913 (2007). https://doi.org/10.1063/1.2822189.

43. E. Gouvea, M. Lagos, A. Vicente, D. Lopez, I. Agote, J.A. Calero, V. Amigó, Ti-27Nb-8Mo Beta Alloy Developed by Electric Resistance Sintering. Euro PM 2019 - Spark Plasma Sintering.

44. A. Amigó-Mata, E. Gouvea, M.A. Lagos, D. López, I. Jesús-Romero, I. Agote, A. Vicente-Escuder, J.A. Calero, Effect of ERS Process Parameters on the Microstructure and Mechanical Properties of Ti6AI4V, Euro PM2019 - Spark Plasma Sintering.

45. P. Li, X. Ma, D. Wang, H. Zhang, Microstructural and Mechanical Properties of $\beta$-Type Ti-Nb-Sn Biomedical Alloys with Low Elastic Modulus. J. Met. 9, 712 (2019). https://doi:10.3390/met9060712.

46. E.P. Utomo, I. Kartika, A. Anawati, Effect of Sn on mechanical hardness of as-cast Ti-Nb-Sn alloys. (2018) https://doi:10.1063/1.5038328.

47. S.S. Da Rocha, G.L. Adabo, G.E.P. Henriques, M.A. Nóbilo, Vickers hardness of cast commercially pure titanium and Ti-6Al-4V alloy submitted to heat treatments. Braz. Dent. J. 17, 126-129 (2006). https://doi:10.1590/s0103-64402006000200008.

48. C.R.M. Afonso, K. Martinez-Orozco, V. Amigo, C.A.D. Rovere, J.E. Spinelli, C. S. Kiminami, Characterization, corrosion resistance and hardness of rapidly solidified Ni-Nb alloys. J. Alloys Compd. 829, 154529 (2020). https://doi.org/10.1016/j.jallcom.2020.154529.

49. N. Mavros, T. Larimian, J. Esqivel, R.K. Gupta, R. Contieri, T. Borkar, Spark plasma sintering of low modulus titanium-niobium-tantalum-zirconium (TNTZ) alloy for biomedical applications. Materials \& Design. 108163 (2019). https://doi:10.1016/j.matdes.2019.108163.

50. Q. Kong, X. Lai, X. An, W. Feng, C. Lu, J. Wu, C. Wu, L. Wu, Q. Wang. Mater. Today Commun. 23, 101130 (2020). https://doi.org/10.1016/j.mtcomm.2020.101130. 
51. F.E.T. Heakal, K.A. Awad, Electrochemical corrosion and passivation behavior of titanium and its Ti-6AL4V alloy in low and highly concentrated HBr solutions. Int. J. Electrochem. Sci. 7, 6539-6554 (2011).

52. A.A. Ahmed, M. Mhaede, M. Wollmann, L. Wagner, Effect of micro shot peening on the mechanical properties and corrosion behavior of two microstructure Ti-6Al-4V alloy. Appl. Surf. Sci. 363, 50-58 (2016). https://doi.org/10.1016/j.apsusc.2015.12.019.

\section{Figures}

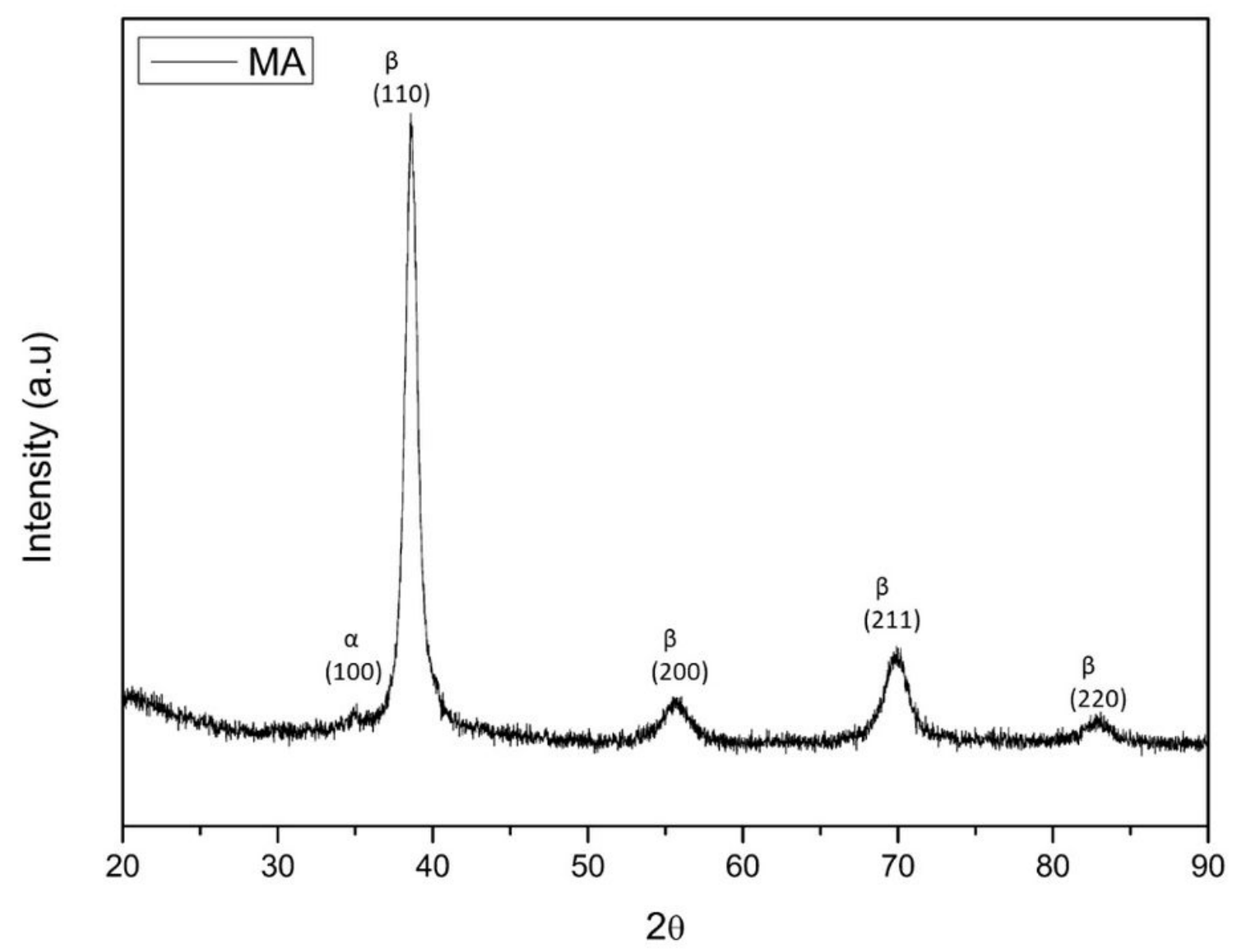

Figure 1

XRD pattern of powders after $72 \mathrm{~h}$ of MA. 


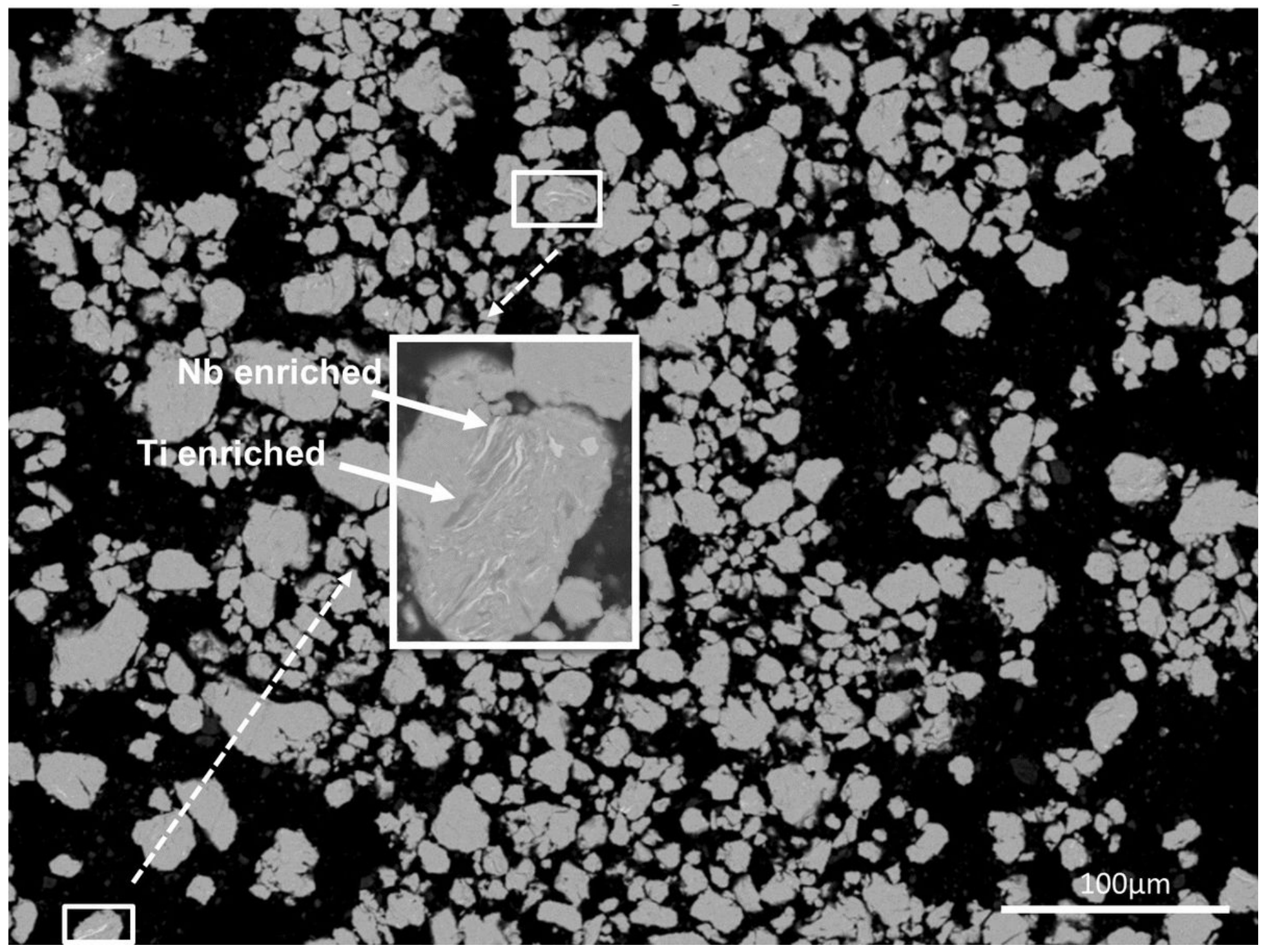

Figure 2

SEM-Backscattered electrons image of cross section of powders after $72 \mathrm{~h}$ milling process. 

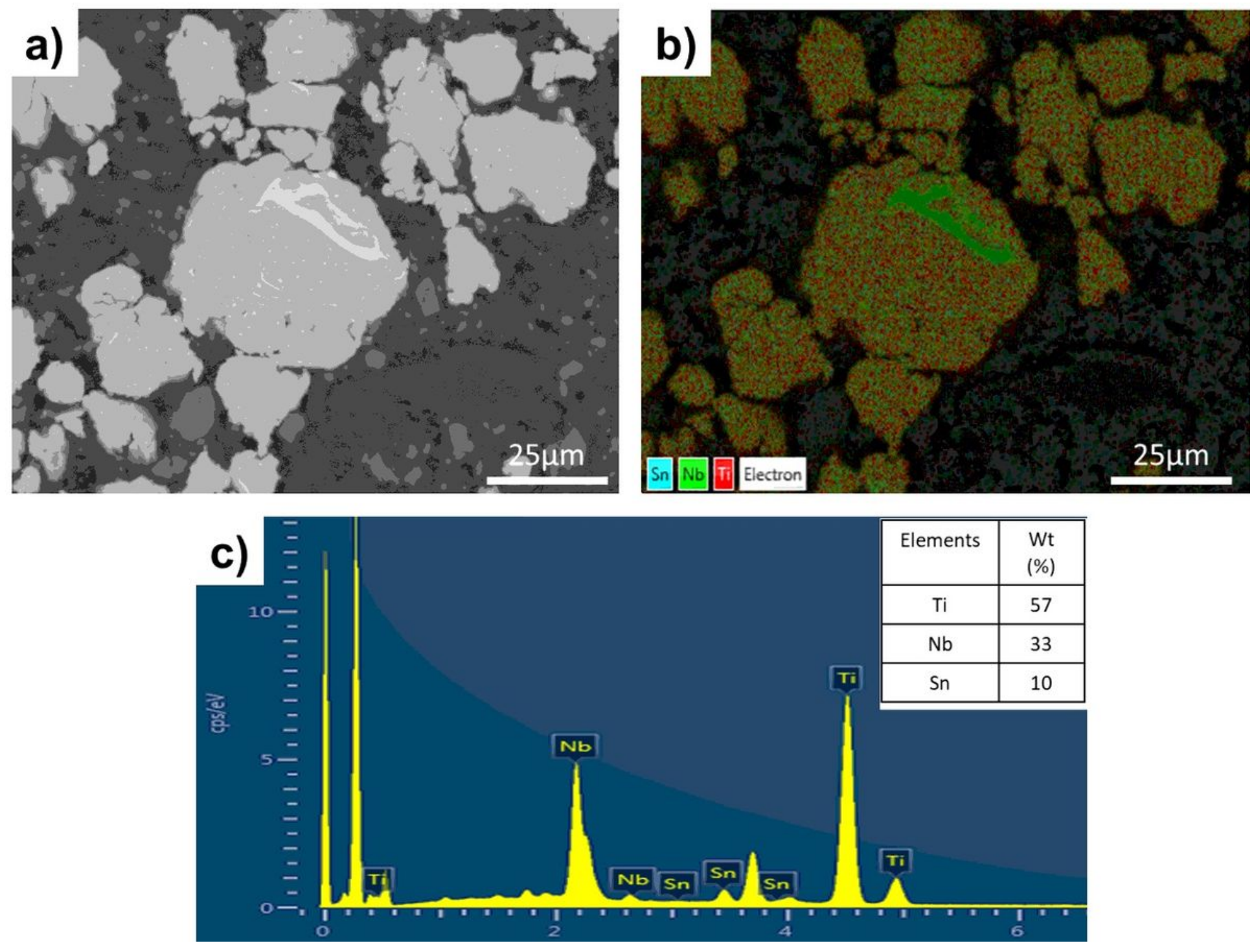

Figure 3

a) SEM-Backscattered electrons image of cross section of powders after $72 \mathrm{~h}$ milling process. b) Micrograph merge of $\mathrm{Ti}, \mathrm{Nb}$ and $\mathrm{Sn}$ maps. c) SEM-EDS analysis of powders milled after $72 \mathrm{~h}$. 
a)

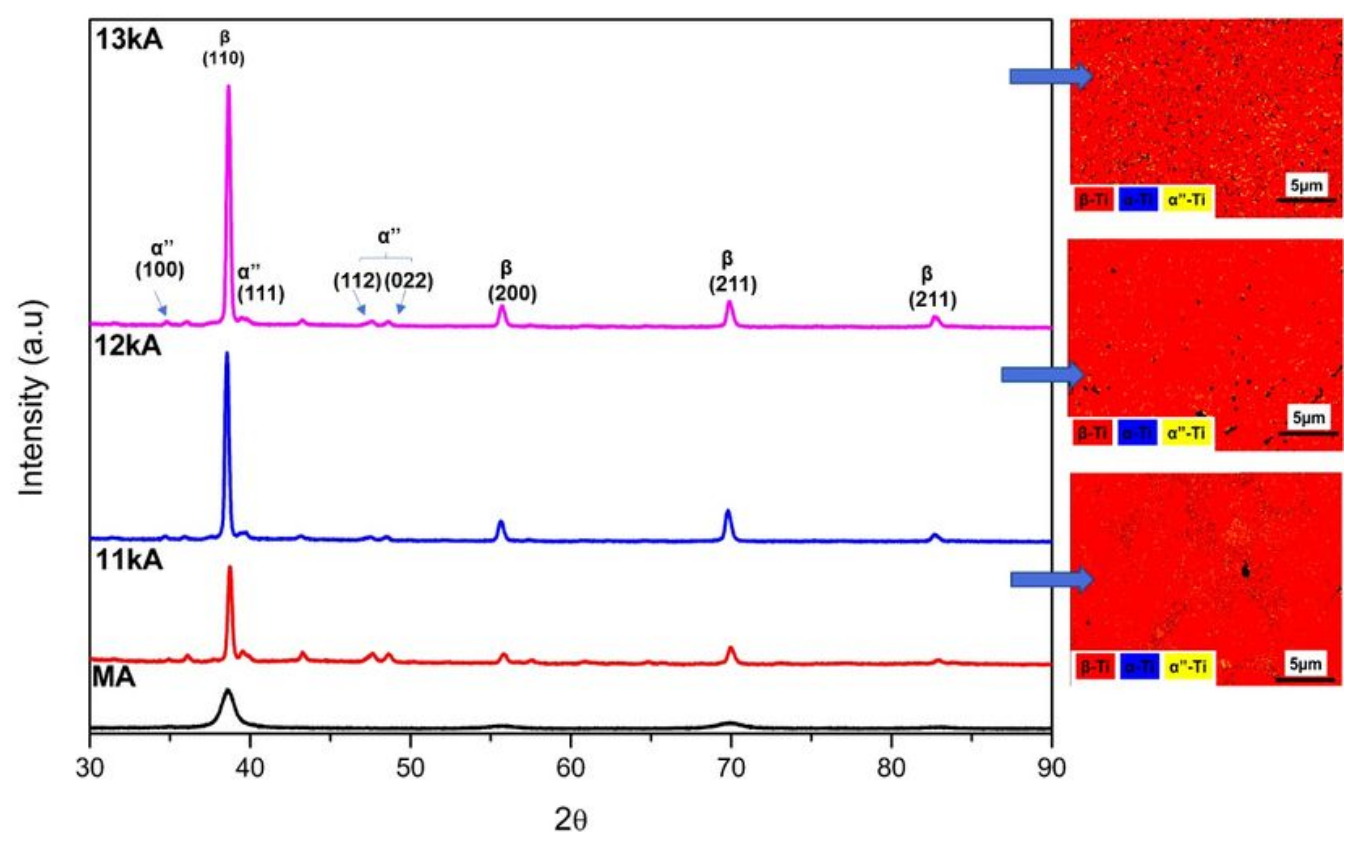

b)

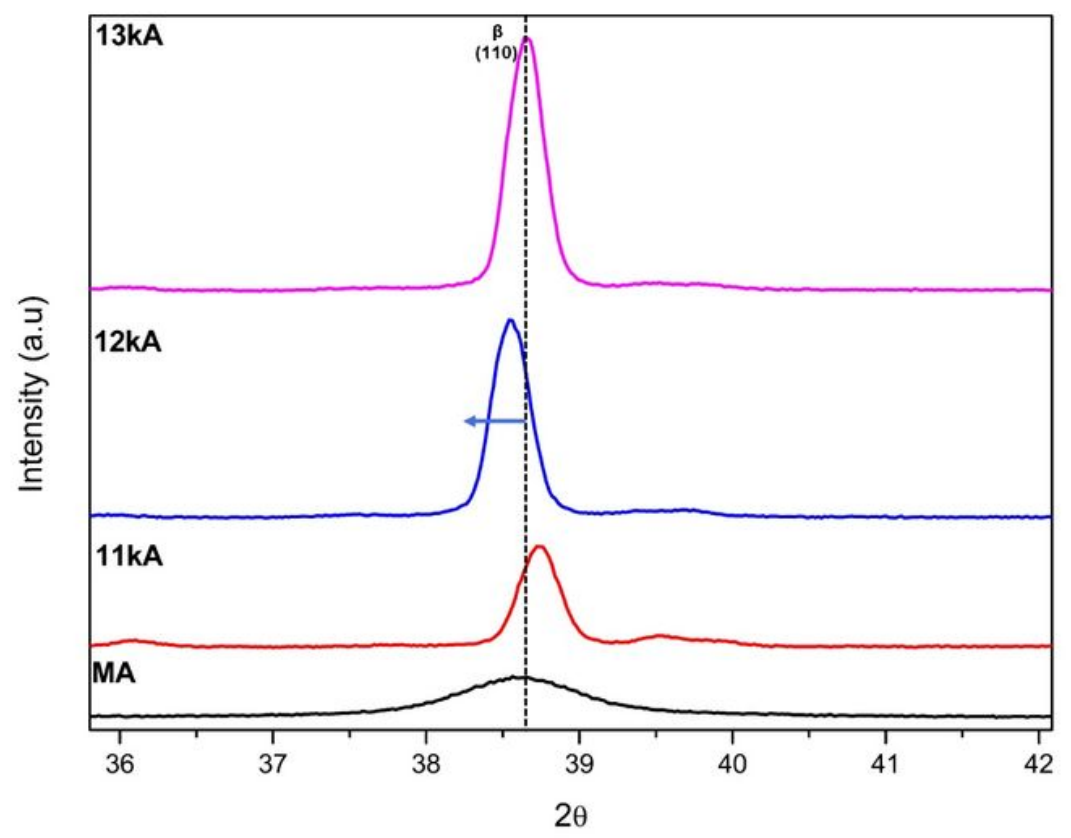

Figure 4

Structural study in the central zone of the samples. a) XRD pattern of powders after MA for 72h and EBSD contrast phase micrographs in the central zone of the samples b) Bragg reflections Profiles of the peak of $\beta$ phase represented by the $\{110\}$ plane of milled Ti-34Nb-6Sn and sintered at 11,12 and $13 \mathrm{kA}$ by ERS. 
a)

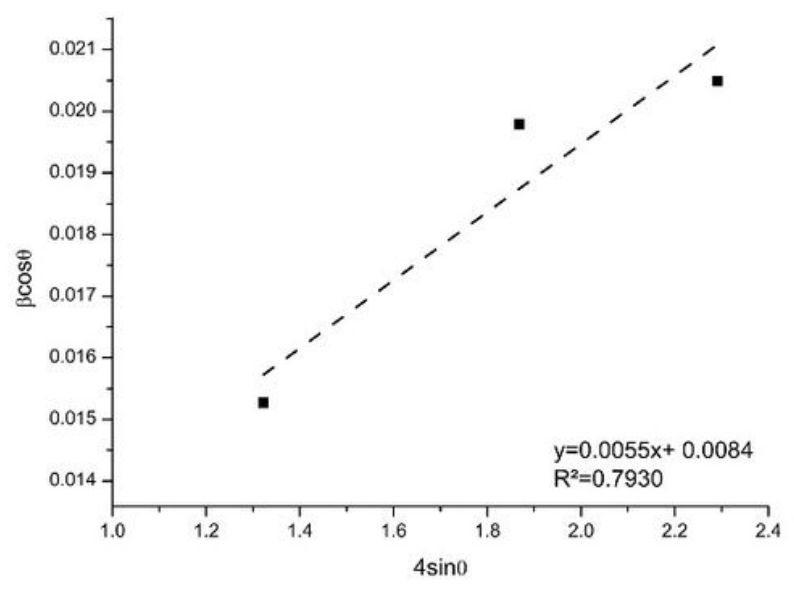

c)

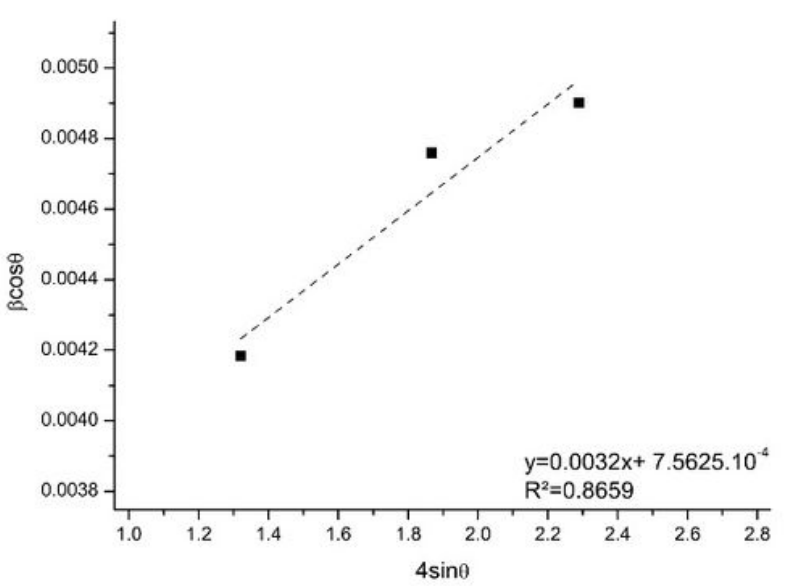

b)

- $11 \mathrm{kA}$

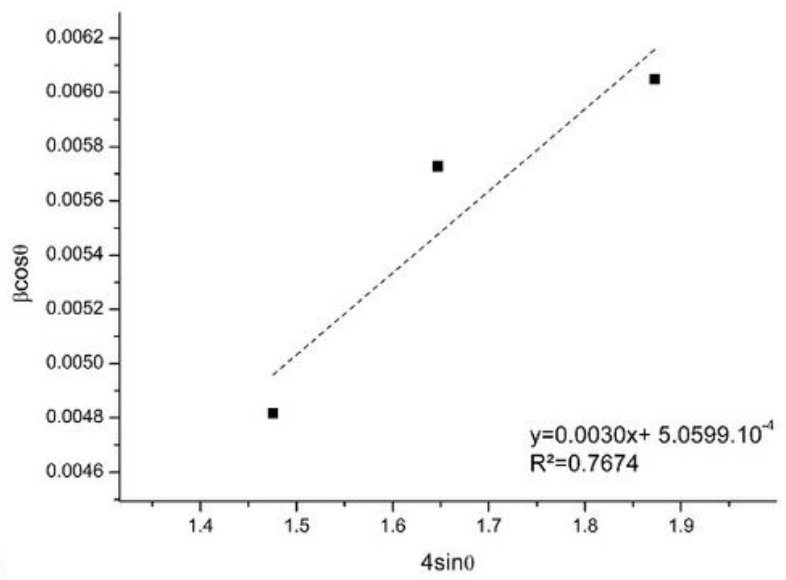

d)

- 12kA

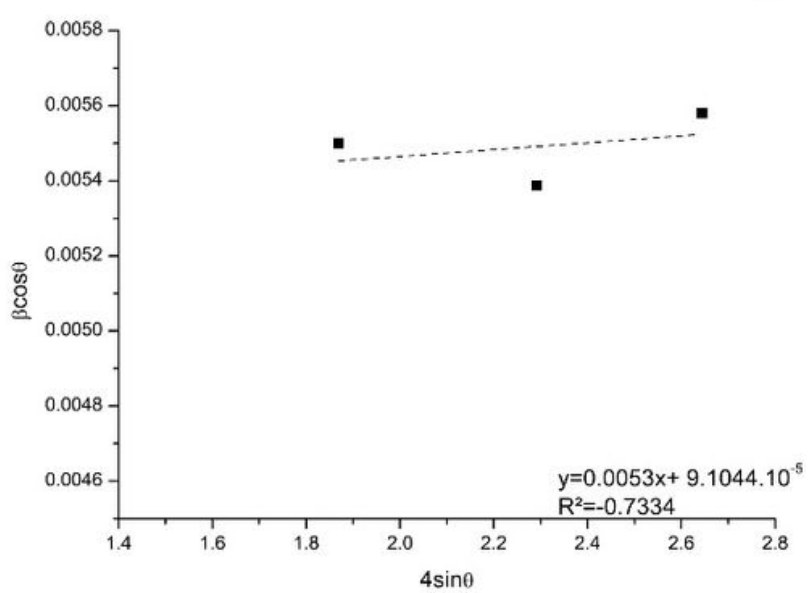

\section{Figure 5}

Linear fit plot for milled and sintered of Ti34Nb-6Sn alloy.a) Linear fit plot of the milled powders for $72 \mathrm{~h} . \mathrm{b}$ ) Linear fit plot of the Ti-34Nb-6Sn consolidated by ERS at 11kA c) Linear fit plot of the Ti-34Nb-6Sn consolidated by ERS at 12kA and d) Linear fit of the Ti-34Nb-6Sn consolidated by ERS at 13kA. 

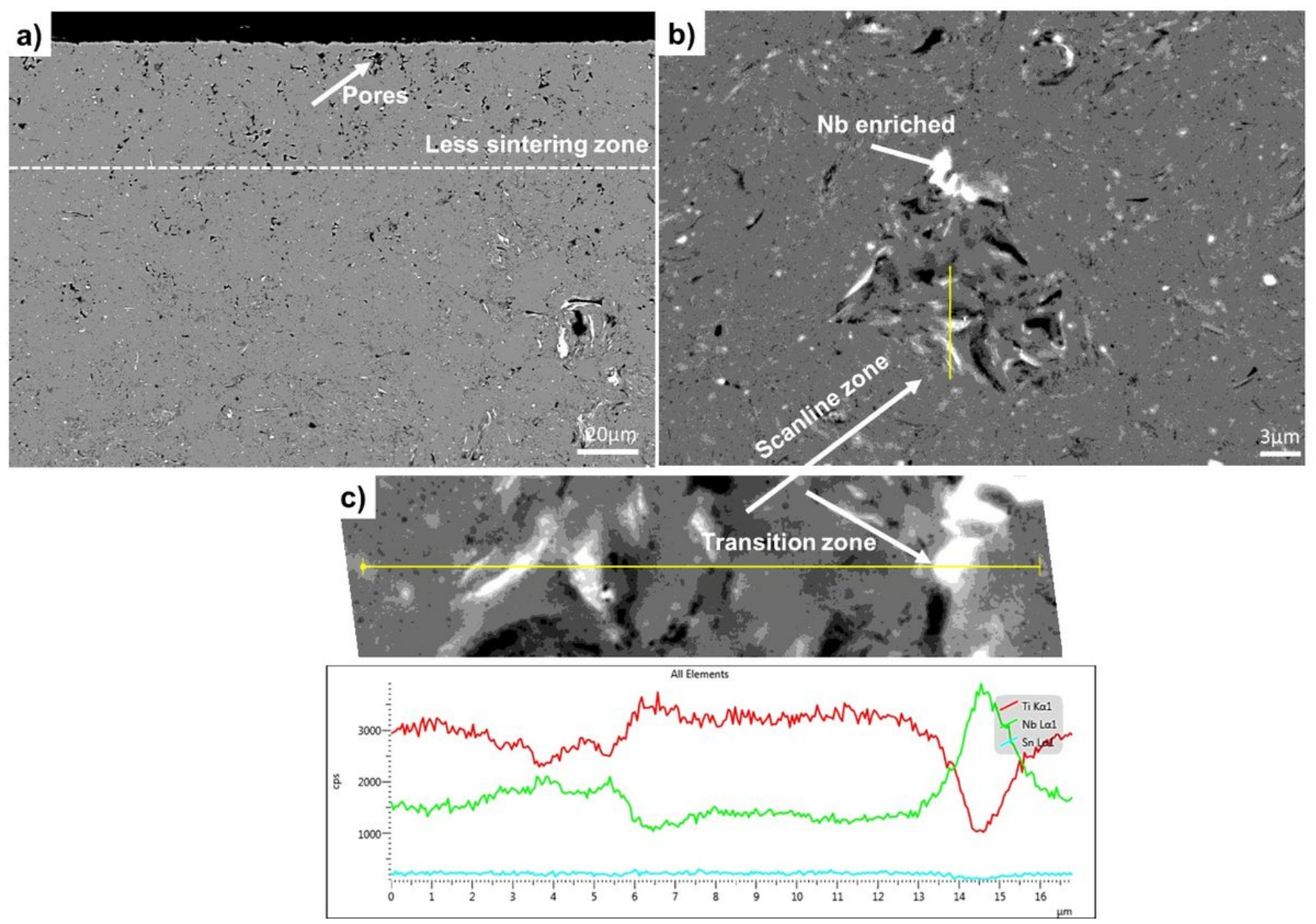

\section{Figure 6}

Linear fit plot for milled and sintered of Ti34Nb-6Sn alloy.a) Linear fit plot of the milled powders for $72 \mathrm{~h}$. b) Linear fit plot of the Ti-34Nb-6Sn consolidated by ERS at 11kA c) Linear fit plot of the Ti-34Nb-6Sn consolidated by ERS at $12 \mathrm{kA}$ and d) Linear fit of the Ti-34Nb-6Sn consolidated by ERS at $13 \mathrm{kA}$. 

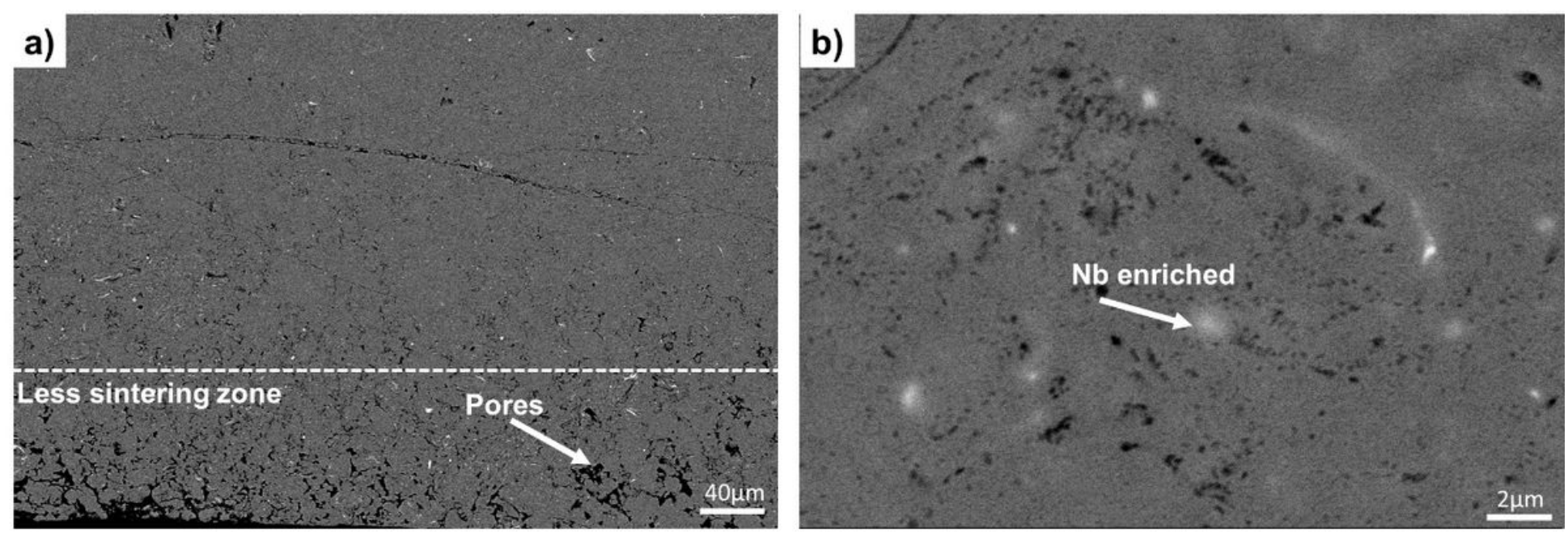

\section{c)}

\section{Figure 7}

SEM-Backscattered electrons images of Ti-34Nb-6Sn consolidated via ERS at 12kA. a) Image of the peripheral region, indicating low sintering. b) Details obtained from an intermediate zone between the peripheral and central regions. c) Details obtained from the central region. 

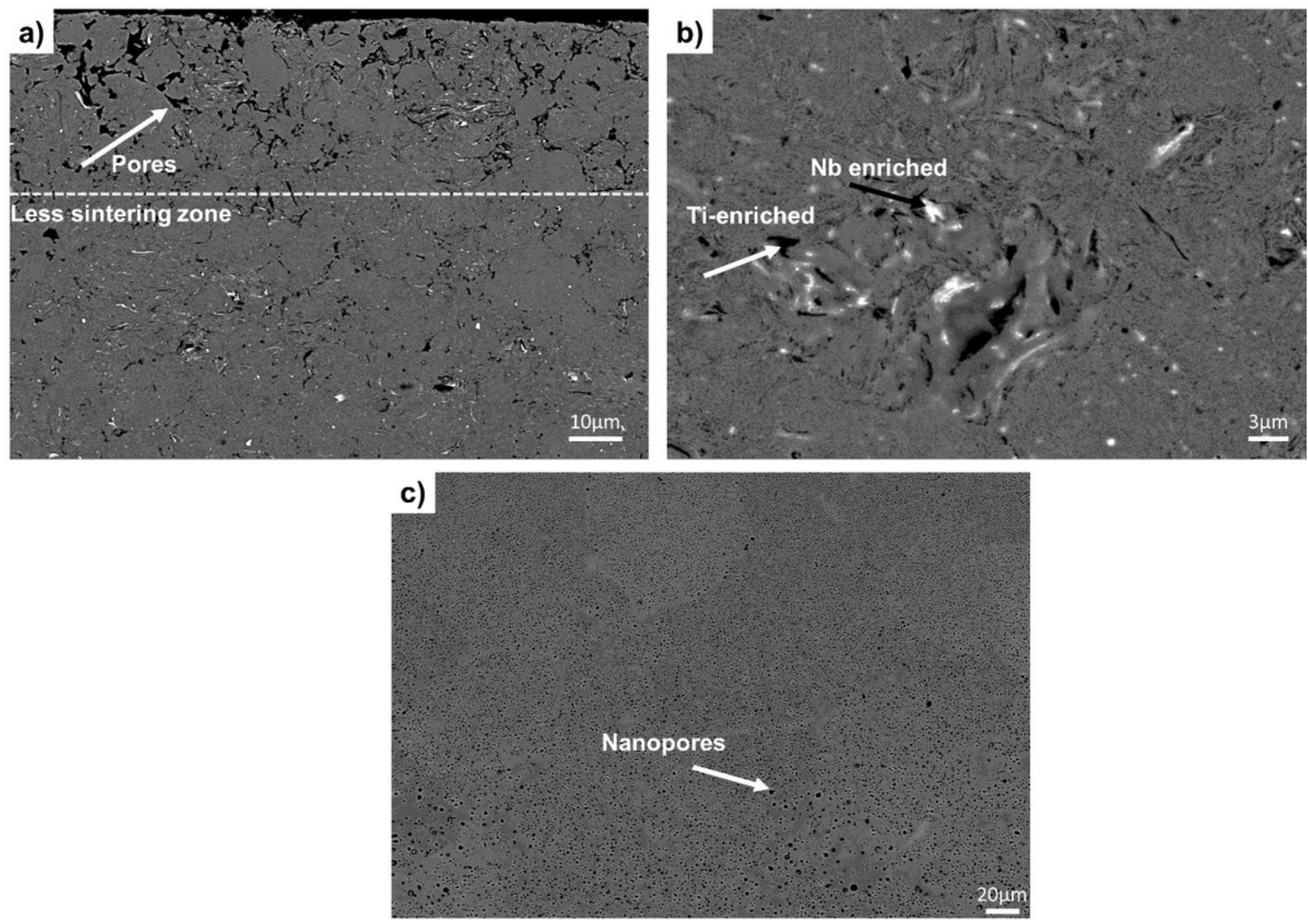

\section{Figure 8}

SEM-Backscattered electrons images of Ti-34Nb-6Sn consolidated via ERS at 13kA. a) Image of the peripheral region, indicating low sintering. $b$ ) Details obtained from an intermediate zone between the peripheral and central regions. c) Details obtained from the central region. 

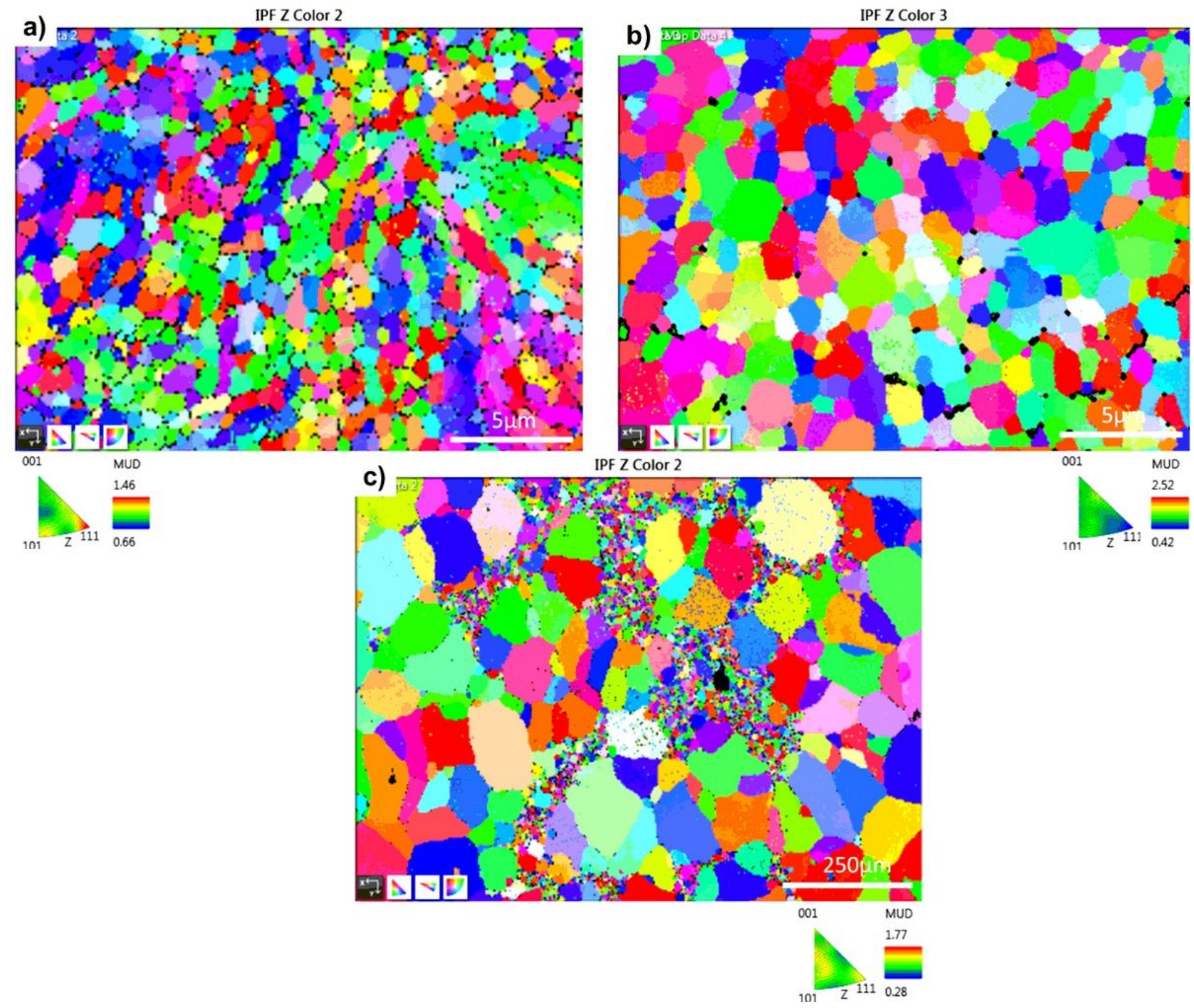

\section{Figure 9}

EBSD IPF-Z maps for Ti-34Nb-6Sn consolidated via ERS at a) 11 kA, b) 12 kA and c) 13 kA. Standard stereographic triangles show a colour-coded schematic grain orientation dependence on different planes. 
a)

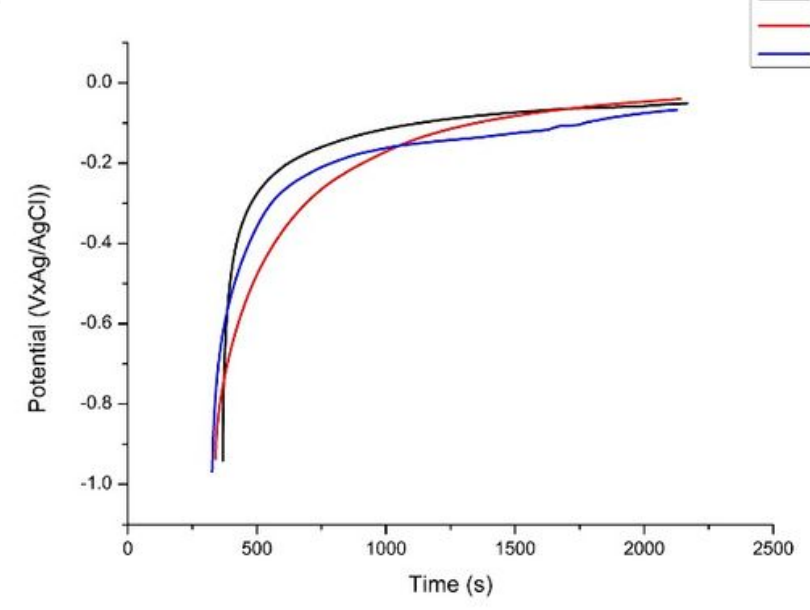

b)

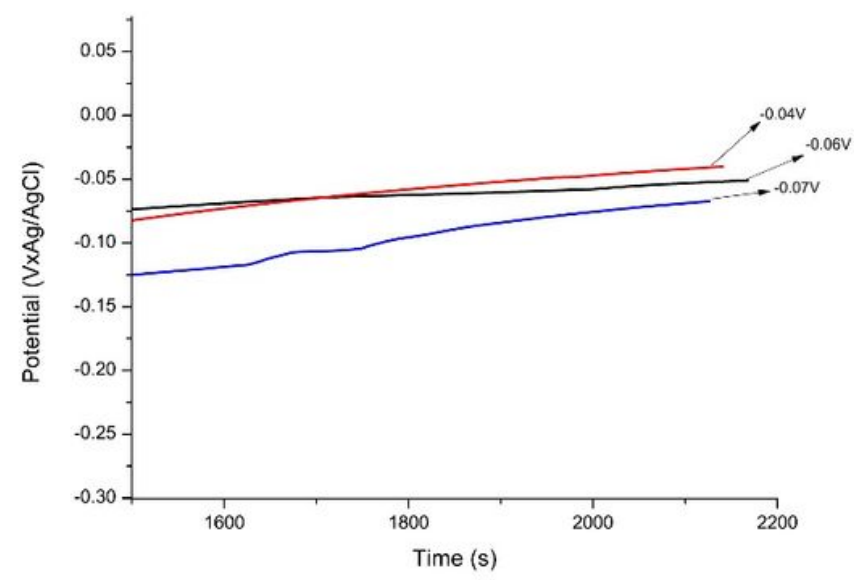

Figure 10

a) OCP curves of the Ti-34Nb-6Sn alloy obtained by the potentiodynamic test carried out under different experimental conditions obtained via ERS. b) indication of stability zones in OCP curves referring to the Figure a).

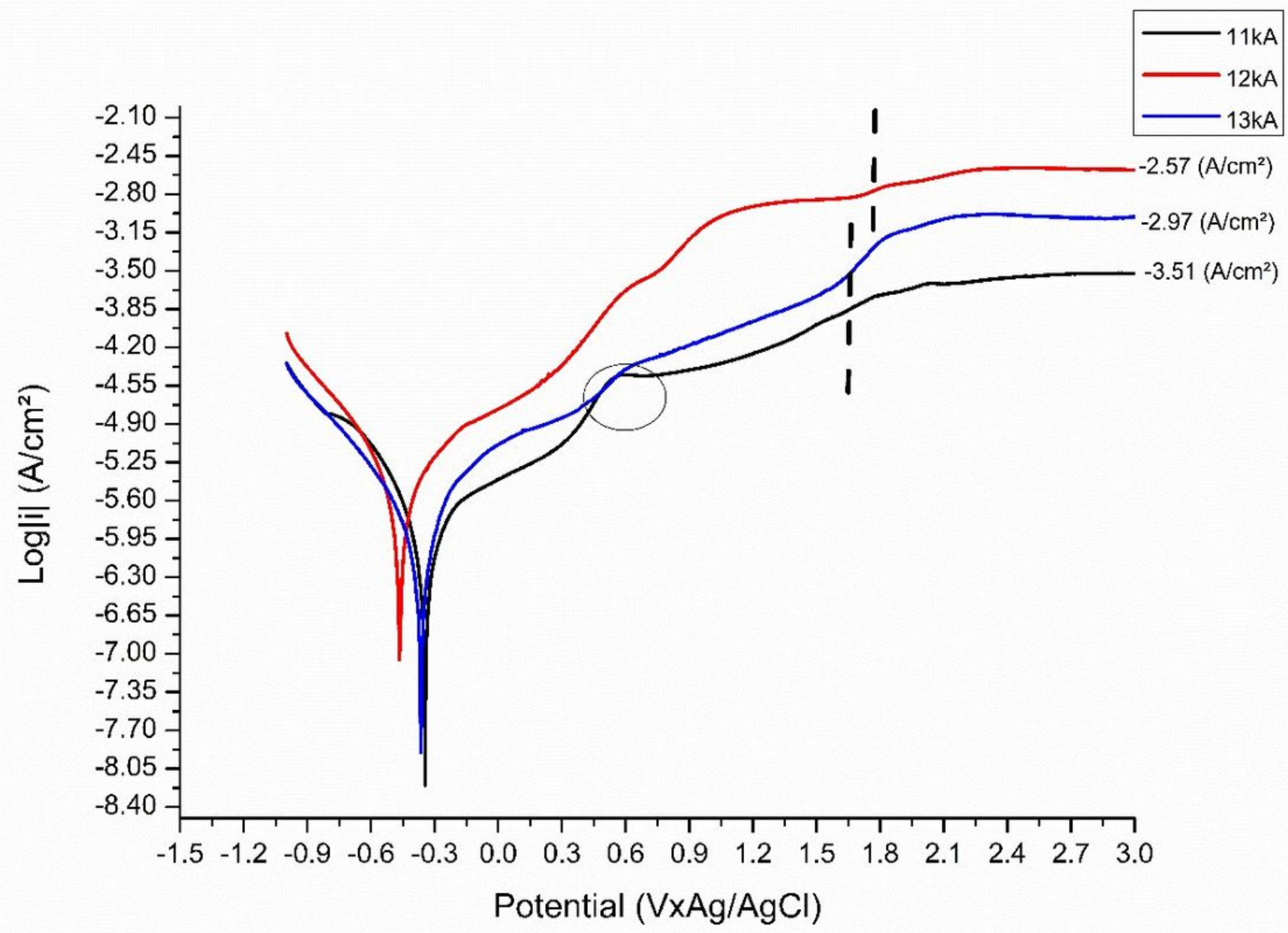

Figure 11 
PPC curves of the Ti-34Nb-6Sn alloy obtained by the potentiodynamic test carried out under the different experimental conditions obtained via ERS.

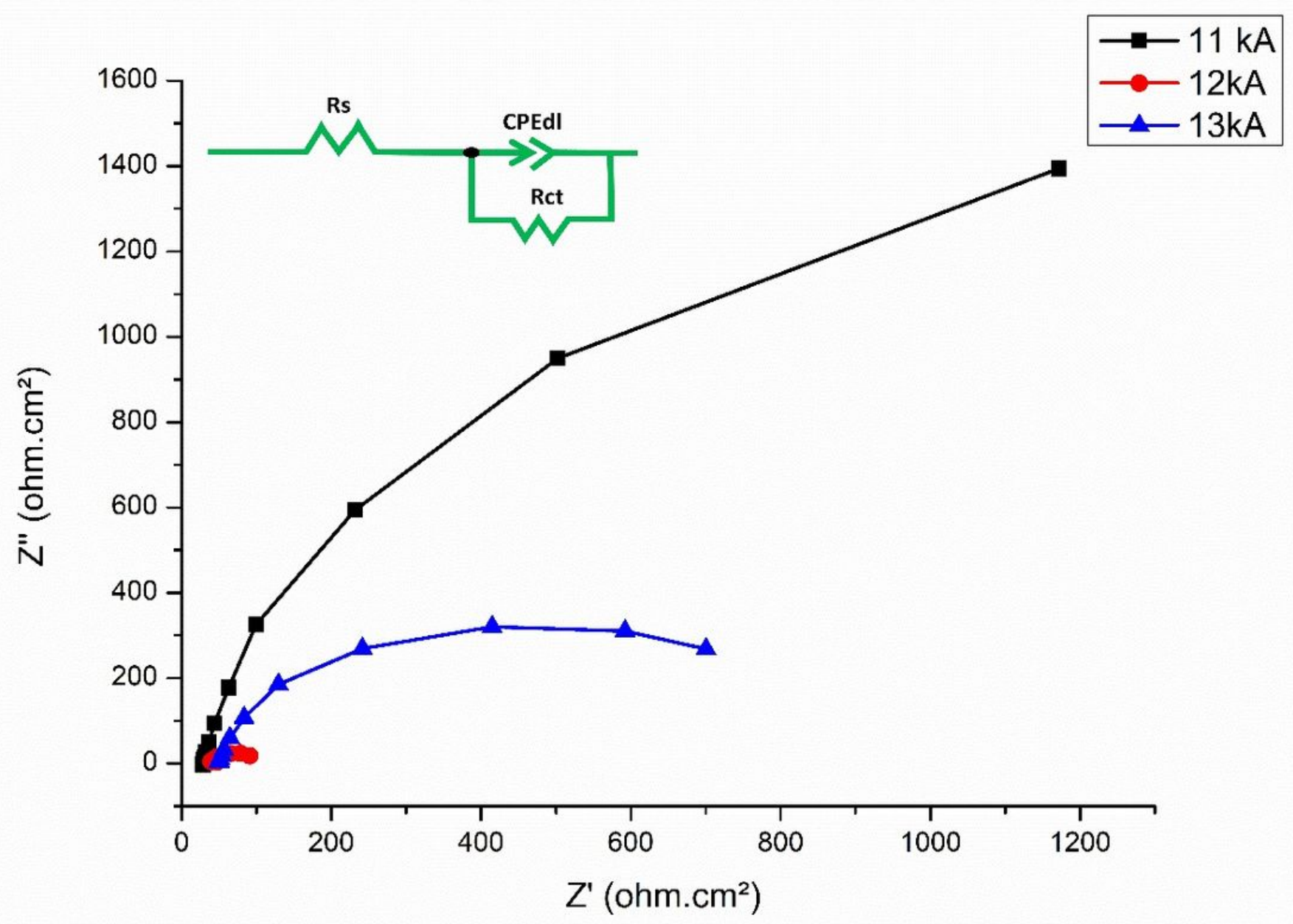

\section{Figure 12}

Typical Nyquist diagram for tested samples and the equivalente electric circuit for EIS data analysis (Rssolution resistance, Rct- circuit resistance, CPEdl-constant phase element (non-ideal capacitance). 